\title{
Functionalization of chitosan with carboxylic acids and derivatives of them: Synthesis issues and prospects of practical use: A review
}

\author{
I. A. Farion ${ }^{1}$, V. F. Burdukovskii ${ }^{1}$, B. Ch. Kholkhoev ${ }^{1,2 *}$, P. S. Timashev ${ }^{3,4}$, R. K. Chailakhyan ${ }^{4,5}$ \\ ${ }^{1}$ Baikal Institute of Nature Management Siberian Department of Russian Academy of Sciences, Sakhyanovoy Str. 6 , \\ 670047 Ulan-Ude, Russian Federation \\ ${ }^{2}$ Buryat State University, Smolina str. 24a, 670000 Ulan-Ude, Russian Federation \\ ${ }^{3}$ Institute for Regenerative Medicine, Sechenov First Moscow State Medical University, Trubetskaya str. 8-2, \\ 119991 Moscow, Russian Federation \\ ${ }^{4}$ Institute of Photonic Technologies, Research Center of Crystallography and Photonics Russian Academy of Sciences, \\ Pionerskaya str. 2, 108840, Troitsk Moscow, Russian Federation \\ ${ }^{5}$ N. F. Gamaleya National Research Center for Epidemiology \& Microbiology of the Ministry of Health of the Russian \\ Federation, Gamaleya str. 16, 123098 Moscow, Russian Federation
}

Received 30 March 2018; accepted in revised form 30 June 2018

\begin{abstract}
The review is devoted to the current state of the investigation works concerning chitosan functionalization with carboxylic acids and derivatives of them, including oxidized carbon nanoparticles such as graphene oxide, oxidized nano diamonds and oxidized carbon nanotubes. The examples of a use of chitosan derivatives in the pharmacology, the regenerative medicine, and other areas are given.
\end{abstract}

Keywords: biopolymers, chitosan, carboxylic acids, regenerative medicine, pharmacology

\section{Introduction}

In connection with an extensive development of new directions on pharmacology and regenerative medicine, including tissues and internal organs engineering, the targeted drug delivery, transplantology, and other fields, the investigators interests have been focused in the more extent on available polysaccharide biopolymers, which are the objects of the nature origin and serve as a scaffold in many organisms of flora and fauna [1-5].

Chitosan is one of the promising and commercially available polysaccharides. It is obtained via the alkali deacetylation of chitin that is a component of the carapace of crabs, shrimps, insects, fungi tissues, and other nature sources [6]. Unlike cellulose and starch, the chitosan macromolecule consists of such repeating units as the fragments of 2-acetamido-2desoxy- $\beta$-D- (a few of them) and 2-amino-2-desoxy$\beta$-D-glucopyranoses (a lot of them). These fragments connect each other across the $\beta(1 \rightarrow 4)$-glucoside bonds. That is, chitosan is poly(aminosaccharide). By present days, the chitin and chitosan structures have been comprehensively studied. Therefore, the detail information on this topic can be searched in articles and reviews, including the references in this review. A large interest to chitosan as a promising object for the tissues and vascular engineering has been arisen due to the presence in its repeating units both hydroxyl and amino groups. The amino groups impart to chitosan such unique properties as solubility into

${ }^{*}$ Corresponding author, e-mail: holh_bat@mail.ru

C BME-PT 
diluted water solutions of monobasic mineral or organic acids with the formation of the polycations that prone to the formation of interpolymeric complexes with polyanionic macromolecules [7], including DNA and RNA [8]. By virtue of the chelating and electron-donating properties of the functional groups, chitosan forms readily complex compounds with the transition metals cations $[9,10]$. Chitosan can also play a role of the effective polymer matrix for the different mineral phosphate fillers; this is important in the view of a design of bone implants [2-4]. The presence of a positive charge on the ammonium groups of the polymeric chains imparts to chitosan the ability to connect with the cellular walls of the pathogenic bacteria $[11,12]$, resulting in a death of them, and with the mucous membranes [13, 14]. In addition, chitosan possesses good adhesion to the stromal cells; this is important for the design of the scaffolds $[4,15,16]$. Chitosan derivatives are used as hydrogels or nanoparticles for the design of the carriers of drugs, the agents for diagnostics of food additives or cancer, as well as for the design of materials for the extraction of toxic heavy metals from wastewaters [17-22].

The functional groups of chitosan, especially the amino groups, give an opportunity of the chemical functionalization of this aminopolysaccharide; this permits one to extent a range of the materials on base of chitosan as well as improving characteristic properties of them. Many of the synthetic ways of a chitosan modification and the directions of a practical use of materials on base chitosan and the derivatives of it were highlighted in the reviews [2, 23-125]. These reviews contain, in general, information classified by the preparation methods of the chitosan derivatives, the properties of these derivatives, and the practical use of them. However, review publications classified by the chitosan modification with carboxylic acids or the derivatives of them are absent.

The unique advantages of this type of modification originate from the uniqueness of carboxylic acids and their derivatives. As is known, carboxylic acids and their derivatives form such common derivatives as esters and amides via the acylation of alcohols (across $\mathrm{OH}$ group) or appropriate amines (across NH or $\mathrm{NH}_{2}$ groups). Free carboxylic acids form ammonium salts with amines as well. It is necessary to mention that carboxylic acids and some of their derivatives (fats, oils, waxes, metabolic products, vitamins, pectin, etc.) are products of natural origin and are ecologically friend substances. In addition, a hydrocarbon chain of carboxylic acids may contain reactive groups, for example, the oxirane, a carbonhalogen bond, and a $\pi$-electron deficient multiple bond conjugated with a $\mathrm{C}=\mathrm{O}$ group. Such a multiple bond can both interact with some nucleophiles as the Michael addition and take part in the (co)polymerization reactions, including the graft ones. Chitosan contains the $\mathrm{OH}$ and $\mathrm{NH}_{2}$ groups that take part in all of the abovementioned reactions with carboxylic acids and their derivatives. Employing all of the diversity of carboxylic acids and their derivatives, including properties of them, one can widely vary both approaches to chitosan modification and properties of modified derivatives.

At the same time, a large stockpiled literature material highlighting the achievements in this direction makes necessary for one to do a systematization of the works concerning the problems of the chitosan modification with carboxylic acids and/or derivatives of them because such an information will be useful for a wide range of researchers, e.g., specialists in the fields of nature polymer chemistry, biomedicine, transplantology, tissue engineering, pharmacology, etc. Therefore, this review is devoted to the methods for chitosan functionalization with carboxylic acids or their derivatives, the properties of the modified derivatives, and the prospects of a practical use of them.

All of the reactions of the chitosan modification relate to the polymer-analogous transformations, the passing of which is specific in relation to the properties a macromolecular substrate. The characteristics of such transformations are widely highlighted in the scientific literature [126]. Hence, it is not necessary to consider them in detail.

It is necessary to explain also that the schemes shown in this review will differ in some extent from analogous ones given in the primary literature sources; this will not distort the essence of the presented information. For example, all of the structure formulas of chitosan are shown as the repeating glucosamine units, without the acetyl glucosamine ones ('chitin units'), which were depicted in the primary literature sources, because they do not take part in the chemical modification reactions. 


\section{Chitosan modification with carboxylic acids and their derivatives without involvement of carboxylic function: Modification across carbochain residue \\ 2.1. Use of reactions of nucleophilic substitution or addition}

The presence of the more reactive groups than the carboxylic ones (or the carboxylate anions) in a carbohydrate fragment of acids predetermines the priority of an interaction of them with chitosan. Here, generally, the reactions of the nucleophilic substitution on a sp ${ }^{3}$-hybridized carbon (in a case of a presence of the oxirane ring or a carbon-halogen bond) or the nucleophilic Michael addition to a $\mathrm{sp}^{2}$-hybridized carbon (in a case of a presence of a $\pi$-electron deficient multiple bond) in carbohydrate fragments occur.

For example, the widely known approach to obtaining sodium salt of caboxymethyl cellulose ( $\mathrm{Na}-\mathrm{CMC}$ ) via the consecutive interactions of fine-crystalline cellulose with $\mathrm{NaOH}$ and then with sodium monochloroacetate [127] was realized with chitosan as well [128] (Figure 1). O-, N-carboxymethyl chitosan with the substitution degree of $0.25-1.19$ containing the $\mathrm{COOH}$ and $[\mathrm{COO}]^{-} \mathrm{Na}^{+}$groups in the side substitutions was synthesized. It was proven that the decrease of molecular masse of native chitosan resulted in the solubility in water at the lower substitution degrees. In addition, the 1-O-carboxymethylated units predominated over the $\mathrm{N}$-carboxymethylated ones as consequence of the preparation of this chitosan derivative in strong alkali media.

Such carboxymethyl chitosans were utilized for obtaining nano-threads by means of the electro-spreading methods. These nano-threads can be used in different areas, including regenerative medicine [129]. Besides, carboxymethyl chitosans could be also utilized as a polymer matrix for the design of the biologically compatible and low-toxic nanocomposites, for example, with hybrid quantum dots such as $\mathrm{CdSe} / \mathrm{ZnS}$ [130] and folate $/ \mathrm{Fe}_{3} \mathrm{O}_{4} / \mathrm{CdTe}$ [131]. While these quantum dots themselves are highly toxic, the

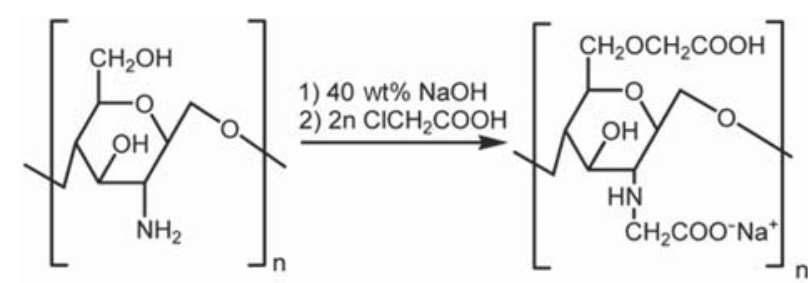

Figure 1. Carboxymethylation of chitosan in alkali media. chelating properties of the functional groups of carboxymethyl chitosans with respect to $\mathrm{Cd}^{2+}$ and $\mathrm{Zn}^{2+}$ have restricted severely this negative characteristic of the abovementioned quantum dots. The nanocomposites of such a type, by virtue of the visualization effect, could be promising as fluorescent labels to study processes passing in one-cell organisms, for example, in yeasts.

There is an example of the design of materials based on 1-O-carboxymethylchitosan for removing heavy metals from wastewater. For this, 1-O-carboxymethylchitosan was thermally cross-linked with hemicellulose [132]. The cross-links were formed as azomethine bonds between the O-carboxymethylchitosan repeating units and the terminal groups of hemicellulose. It was proven that the maximal adsorption capacity of this cross-linked material with respect to $\mathrm{Ni}^{2+}, \mathrm{Cd}^{2+}$ and $\mathrm{Cu}^{2+}$ exceeded values of this parameter for many known adsorbents of heavy metals cations. In the work [133], 1-O-carboxymethylchitosan with the grafting degree of $65 \%$ was utilized for the design of nanocapsules via an interaction of it with polyamidoamine dendrimer (PAMAM). More specifically, the carboxymethylchitosan macromolecules enveloped a PAMAM dendrimer containing doxorubicin as the anti-tumor drug. The surface of the PAMAM dendrimer had many of the positively charged ammonium groups that formed ionic links with the $[\mathrm{COO}]^{-}$of carboxymethylchitosan. That is, the formation of the nano interpolymer complex as capsules took place. These nano capsules were sensitive to $\mathrm{pH}$; they opened at dropping $\mathrm{pH}$ due to the charge inversing effect, releasing a doxorubicin/ PAMAM complex which then permeated into a tumor cell.

Unsaturated carboxylic acids or their derivatives containing a $\pi$-electron-deficient multiple bond conjugated with a carbonyl functional group interacted with chitosan according to the Michael addition [134-136]. In this case, the $\mathrm{NH}_{2}$ groups, being more nucleophilic than the $\mathrm{OH}$ groups, underwent alkylation reaction (Figure $2 \mathbf{1}$ ). In addition, these $\mathrm{NH}_{2}$ groups underwent the epoxy-alkylation in the reactions with the highly strained oxirane rings of the carbohydrate moieties of carboxylic acids [137, 138] (Figure 2 2). These reactions were passed without any by-products elimination; this is the positive factor when the similar processes run in not only solutions but also a solid phase, for example, in films. 


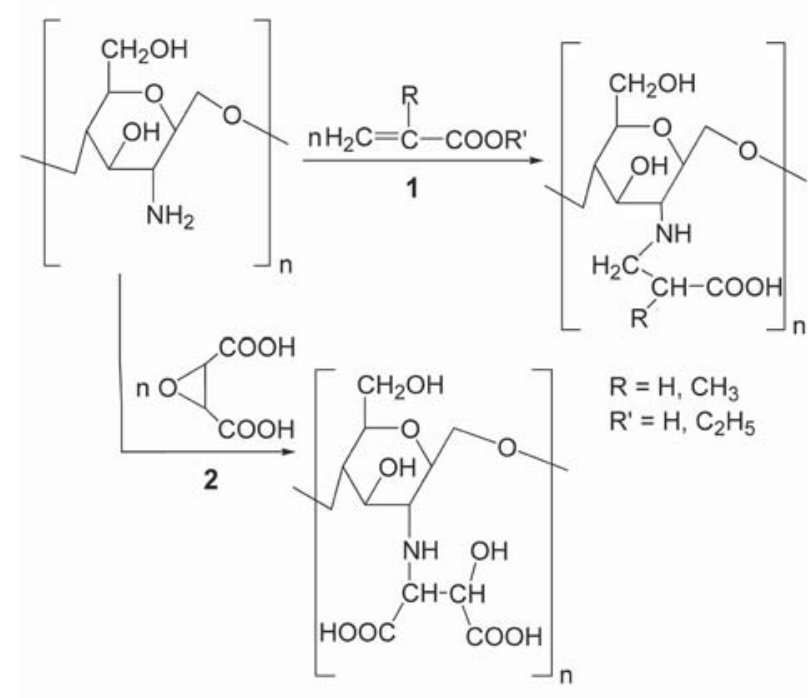

Figure 2. Alkylation and epoxy-alkylation of chitosan with acrylic acids or their derivatives and oxirane-2,3dicarboxylic acid, respectively.

\subsection{Use of reactions of graft polymerization via polyaddition across multiple bonds}

Feature of this approach to grafting the carboxylic acids or their derivatives onto the chitosan macromolecule is the initiation of the macromolecular free radicals via the oxidative elimination of electrons from the lone pair of a nitrogen and/or an oxygen under the impact of both the peroxides (for example, $\mathrm{H}_{2} \mathrm{O}_{2},\left(\mathrm{NH}_{4}\right)_{2} \mathrm{~S}_{2} \mathrm{O}_{8}, \mathrm{~K}_{2} \mathrm{~S}_{2} \mathrm{O}_{8}$ ) or $\mathrm{Ce}^{4+}$ (for example, $\left.\mathrm{Ce}\left(\mathrm{NH}_{4}\right)_{2}\left(\mathrm{NO}_{3}\right)_{6}\right)$ as redox initiators and $\gamma$-radiation. After this, the formed macromolecular radical centers initiate the chain polymerization of unsaturated acids, for example, (meth)acrylic ones or their derivatives. Ultimately, the graft copolymers of poly(acids) or their derivatives that are grafted across a macromolecular hydrocarbon moiety are formed. All of the non-crosslinked graft copolymers, in general, possess a good solubility in aqueous media as result of weakening the interactions between the chitosan macromolecules.

For example, the free radical graft polymerization of acrylamideglycolic acid onto chitosan, which was initiated with $\left(\mathrm{NH}_{4}\right)_{2} \mathrm{~S}_{2} \mathrm{O}_{8}$ in water solution, resulted in a graft copolymer in high yields [5] (Figure 3).

This graft copolymer, by virtue of the presence of a large amount of the $\mathrm{COOH}, \mathrm{NH}, \mathrm{NH}_{2}$, and $\mathrm{OH}$ functional groups, was a good complex-forming agent for $\mathrm{Ca}^{2+}$ and possessed a compatibility with hydroxyapatites. This characteristic promotes for chitosangraft-poly(acrylamideglycolic acid) to be the perspective ecologically friendly material for the design of the bone implants.
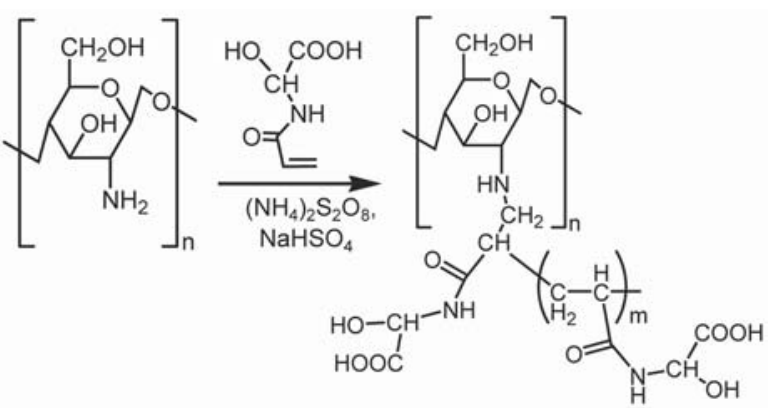

Figure 3. Graft polymerization of acrylamideglycolic acid onto chitosan.

For the analogous graft polymerization, previously modified chitosans were also utilized. For example, the graft polymerization of methacrylic acid onto 1-Ohydrxypropyl chitiosan was investigated [139] (Figure 4).

It was proven that the grafting efficiency was influenced by the concentration of the initial monomer and initiator, temperature and the processing time. The obtained graft copolymers possessed good solubility in aqueous media. Besides, the presence of the hydroxypropyl substituents produced spatial hindrances on the initial reaction step, interfering with the denser packing of macromolecules; this favored the grafting process.

An interesting approach that consisted in the graft copolymerization of methylmethacrylate onto 1-O-carboxymethylchitosan was realized in the work [140]. $\left(\mathrm{NH}_{4}\right)_{2} \mathrm{~S}_{2} \mathrm{O}_{8}$ was utilized as the redox initiator. The maximal grafting extent of about $1900 \%$ was reached at $m$ equal to 18. Along with this, the processes of the deacetylation of the 'chitine' units proceeded. 1-O-carboxymethylchitosan swelled in neutral aqueous media to a higher extent than native chitosan. It contained also a lot of free $\mathrm{NH}_{2}$ groups, promoting the effective course of the graft copolymerization process. Such graft copolymers possessed the ability not only to swell in neutral aqueous media but also to be soluble in them.

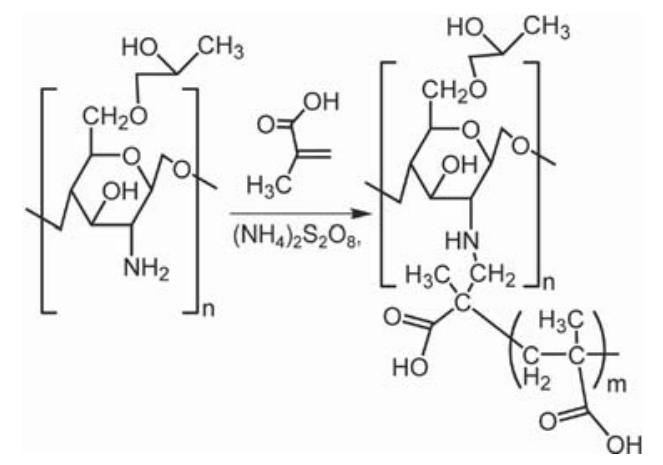

Figure 4. Graft polymerization of methacrylic acid onto chitosan. 
The abovementioned 1-O-carboxymethyl- and 1-Ohydroxypropylchitosans were also processed by the graft polymerization with monosodium salt of maleic acid in presence of $\left(\mathrm{NH}_{4}\right)_{2} \mathrm{~S}_{2} \mathrm{O}_{8}$ to yield 1-O-carboxymethyl- or 1-O-hydroxypropylchitosan-graftpoly (maleic acids) [141]. The maximal grafting extent of about $1720 \%$ was reached. Such graft copolymers revealed high activity in the capture of the superoxide anion-radical, $\left[\mathrm{O}_{2}\right]^{-}$, one of the strongest oxidizers and toxic oxygen forms. Authors explained that this behavior with respect to $\left[\mathrm{O}_{2}\right]^{-} \cdot$ was due to the presence of more available functional groups, than in native chitosan, because the modification followed by the graft copolymerization resulted in a 'loosening' of the macromolecular structure, and, as consequence, the decrease of the amount of the hydrogen bonds occurred.

Redox systems were also utilized as the initiating reagents for the graft (co)polymerization of acrylic acids derivatives. So, the processes of the graft polymerization of methyl esters of acrylic or methacrylic acids onto chitosan that were initiated with $\mathrm{K}_{2} \mathrm{~S}_{2} \mathrm{O}_{8}$ in the presence such co-initiators as $\mathrm{MnCl}_{2}, \mathrm{CuCl}_{2}$, as well as ammonium tartrate or oxalate were studied [142]. It was evidenced that the grafting efficiency depended on the kind of the initiating system. The maximal value of the grafting extent of $80 \%$ was reached with the use of methylacrylate as monomer in the presence of $\mathrm{K}_{2} \mathrm{~S}_{2} \mathrm{O}_{8}$ /ammonium tartrate as the initiating system.

The graft copolymerization of acrylates onto chitosan can be also initiated with the system of $\mathrm{H}_{2} \mathrm{O}_{2} /$ $\mathrm{Fe}\left(\mathrm{NH}_{4}\right)_{2}\left(\mathrm{SO}_{4}\right)_{2}$, so-called 'Fenton system' [143]. Wherein, the maximal yield of the graft copolymer of $332 \%$ was reached. The graft copolymer was not soluble in dilute aqueous solutions of $\mathrm{CH}_{3} \mathrm{COOH}$, methanol, acetone, and in mixture of ethanol $/ 2 \%$ water $\mathrm{CH}_{3} \mathrm{COOH}$ solution, it only swelled in them. The absence of solubility in dilute aqueous solutions of $\mathrm{CH}_{3} \mathrm{COOH}$, in which native chitosan is soluble, may be related to the formation of intermolecular cross-links due to the donor-acceptor bonds between the functional groups of chitosan together with the grafted methacrylate residues and $\mathrm{Fe}^{3+}$.

Besides acrylic and maleic acids or their derivatives, vinyl esters of carboxylic acids were also utilized for the chitosan modification via the graft copolymerization. For example, the synthesis of chitosan-graft-poly (vinyl acetate) was carried out via the interaction of chitosan dissolved in $2 \%$ aqueous $\mathrm{CH}_{3} \mathrm{COOH}$ solution with vinylacetate where $\mathrm{Ce}\left(\mathrm{NH}_{4}\right)_{2}\left(\mathrm{NO}_{3}\right)_{6}$ was utilized as the redox initiator [144]. The maximal grafting efficiency of $35.7 \%$ was reached; this revealed a competition between the major graft polymerization reaction and the minor vinylacetate homopolymerization. When the chitosan substrate quantity enlarged, the maximal grafting efficiency increased. In addition, it was revealed that the swelling extent of such chitosan graft copolymers in aqueous media at $\mathrm{pH} \sim 6.0$ enriched, when the grafting efficiency increased.

To obtain the cross-linked and grafted onto chitosan carbochain polymers with the side $\mathrm{COOH}$ groups, the in situ radical graft polymerization of metacrylic acid onto succinoyl chitosan was carried out in aqueous medium in the presence both $N, N^{\prime}$-methylenediacrylamide as the crosslinking agent and $\left(\mathrm{NH}_{4}\right)_{2} \mathrm{~S}_{2} \mathrm{O}_{8}$ as the water soluble photoinitiator [145]. Crosslinked succinoylchitosan-graft-poly(metacrylates) were synthesized. They could be perspective as drug carriers, for example, for a targeted delivery of theophyllin.

Analogous to the previous example, the in situ radical graft polymerization of methacrylamide onto chitosan was carried out in the presence of $N, N^{\prime}$-methylenediacrylamide and in $2 \%$ water solution of $\mathrm{CH}_{3} \mathrm{COOH}$ where $\left(\mathrm{NH}_{4}\right)_{2} \mathrm{~S}_{2} \mathrm{O}_{8}$ was utilized as the water soluble photoinitiator [146].

In the work [147], another approach to obtain 3D graft copolymers, which consisted in grafting itaconic acid onto the $\mathrm{NH}_{2}$ groups of the chitosan previously crosslinked with glutaric dialdehyde, was taken. Chitosangraft-poly(itaconic acid) cross-linked across the azomethyne bonds (Figure 5) was a good complexforming agent and could be used for the adsorption of toxic ions such as $\mathrm{Cd}^{2+}$ or $\mathrm{Pb}^{2+}$ from aqueous solutions, and the complex-forming characteristics depended on the $\mathrm{pH}$ of media.

Besides the abovementioned redox radical initiators, the graft polymerization under $\gamma$-irradiation of ${ }^{60} \mathrm{Co}$ was also possible. For example, the chitosan modification via the graft copolymerization of 2-hydroxyethyl(meth)acrylates and $N$-vinylpyrrolidone under $\gamma$-irradiation was carried out in acidified water and in sealed ampoules under inert atmosphere [148]. It was proven that the polymerization degree of the grafted residues was directly proportional to the radiation dose, and insoluble products formed only in extreme cases. Wherein, at the primary initiation step, the 'alcoholic' oxygen atoms of chitosan participated, 


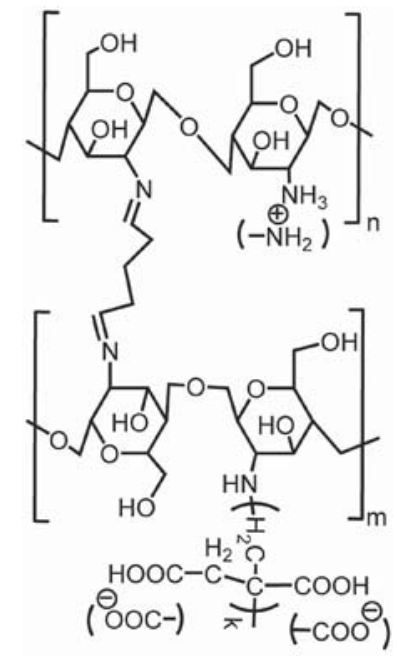

Figure 5. Chitosan-graft-poly(itaconic acid) cross-linked across the azomethyne bonds with glutaric dialdehyde.

unlike the nitrogen atoms of $-\mathrm{NH}_{2}$ when using the redox initiating systems.

\section{Chitosan modification via salt-formation and acylation reactions with the involvement of carboxylic function of acids and their derivatives \\ 3.1. Chitosan modification with free carboxylic acids}

Based on the primary tasks, these reactions with chitosan are used for both obtaining grafted ammonium salts and for the syntheses of grafted amides. Grafted amides are formed from poly(ammonium) salts under high temperatures and/or shearing deformations and/or an ultrasound treatment. At the same time, there are ways to prepare amides grafted onto chitosan under relatively mild conditions via the interaction of chitosan with carboxylic acids in the presence of such condensing systems as carbodiimides/ $\mathrm{N}$-hydroxysuccinimides (or 4-aminopyridines) (See paragraph 3.2.3.).

\subsubsection{Chitosan modification with poly(carboxylic acids)}

If chitosan is modified with native carboxylic acids or carboxylates under mild conditions (low temperatures), poly(ammonium salts) are formed. The ultimate target of these procedures with chitosan is the design of the inter-polymer complexes, so-called protonated chitosan/poly(carboxylates) that are insoluble in water. Here, the electrostatic attraction between the $[\mathrm{COO}]^{-}$groups of poly(acid) residues and the chitosan $\left[\mathrm{NH}_{3}\right]^{+}$groups makes the most contribution to the formation of these inter-polymer complexes along with the hydrogen bonds and the dispersion interactions. (A similar mechanism of complex formation is also characteristic to other poly(acids) such as DNA, RNA, etc. [8], but this theme goes beyond the scope of the present review).

In particular, such complexes were obtained via an interaction of chitosan with poly(maleic), poly(acrylic), and poly((4- $N$-methacrylamido)salicylic) acids, as well as with carboxymethylcellulose or carboxymethylchitin partially cross-linked with either poly (acrylic acids) ('carbopols') or other poly(carboxylic acids) [149-161]. Because of a large quantity of the ionic bonds ('ionic cross-links'), these polymeric complexes were insoluble in aqueous media. They only swelled in these media, forming $\mathrm{pH}$-sensitive hydrogels. Such inter-polymer complexes are widely utilized in the pharmaceutics as drug carriers.

Besides, poly(glutamine acid), biodegradable polypeptide with the side $\mathrm{COOH}$ groups, can be utilized as the poly(carboxylate) component for the design of the inter-polymer complexes. These complexes were obtained via the interaction of poly(glutamine acid) with chitosan-graft-(polyethyleneglycol) [162] or chitosan [163-167]. Such polyelectrolyte complexes in the form of nanocapsules could be used as agents of the targeted carriers of proteins (for example, insulin), antitumor drugs, growth factors of the fibroblast stem cells, and wound-healing materials.

The chitosan/polyacid inter-polymeric polyelectrolyte complexes were also used for preparing complex magnetic spherical nanoparticles with a $\mathrm{Fe}_{3} \mathrm{O}_{4}$ core. For example, the quaternized polyammonium chitosan/sodium alginate $/ \mathrm{Fe}_{3} \mathrm{O}_{4}$ nanoparticles with an average diameter of $68.1 \pm 7.8$ and $162.6 \pm 15.6 \mathrm{~nm}$ were obtained via the step-by-step build-up of the polymer shell on the surface of the $\mathrm{Fe}_{3} \mathrm{O}_{4}$ core [168]. In this case, the sodium alginate macromolecules interacted with the grafted residues with terminal $\left[\mathrm{CH}_{2} \mathrm{~N}\left(\mathrm{CH}_{2}\right)_{3}\right]^{+}$groups. Such nanoparticles possessed good water solubility, efficient cellular penetration and good biocompatibility. They significantly inhibited the growth of gastric tumors.

Nowadays, a trend connected with the growth of the amount of the works related to the design of nanocomposites based on chitosan polymer matrix and oxidized carbon nano fillers is observed. Graphene oxide, oxidized nano diamonds, and oxidized carbon nanotubes that contain, in general, $\mathrm{OH}$ and $\mathrm{COOH}$ groups in their structure along with other oxygen-containing 
functions were utilized as nano fillers [169-173]. Here, oxidized carbon nano fillers may be considered as the poly(carboxylic acid)-like nanoparticles that were capable to form the conjugates with the chitosan macromolecules. In this case, the hydrogen bonds and the ionic interactions between the components took place similar to the abovementioned 'macromolecular' inter-polymeric complexes; this resulted in the solubility loss and the notable rise of the physical and mechanical characteristics at a content of the oxidized carbon nano fillers as low as $0.1-$ 2.0 mass $\%$. At the same time, it is necessary to mention the fact that in the review [174], which is devoted to similar polymeric nanocomposites where graphene oxide was utilized as nano filler, information about the use of chitosan and other polysaccharides as the polymer matrix is absent.

\subsubsection{Chitosan modification with mono- or dicarboxylic acids}

As for lowest monocarboxylic acids, the grafted derivatives, soluble in water, form at low degrees of covalent modification, that is, if a lot of the free amino groups are present. Besides, the dissolution process of chitosan itself in aqueous solutions of monobasic carboxylic acids, where poly(ammonium) salts are formed, can also be attributed to the modification of this poly(aminosaccharide). At the same time, higher fatty monocarboxylic acids or any carboxylic acids with more $\mathrm{COOH}$ groups result in insoluble derivatives that only swell in aqueous media due to both the intermolecular ionic, covalent, ionic-covalent cross-links, and the dramatic increase of hydrophobicity of the grafted polymeric salts.

The solid-phase interaction of native mono- or dicarboxylic acids such as phthalic, succinic, and maleic ones with chitosan in a screw extruder and in absence of solvents and condensing agents was carried out by Akopova and coworkers [175, 176] (Figure 6).

In this case, reaction products with both covalent (amides) and ionic (salts) bonds were obtained. In

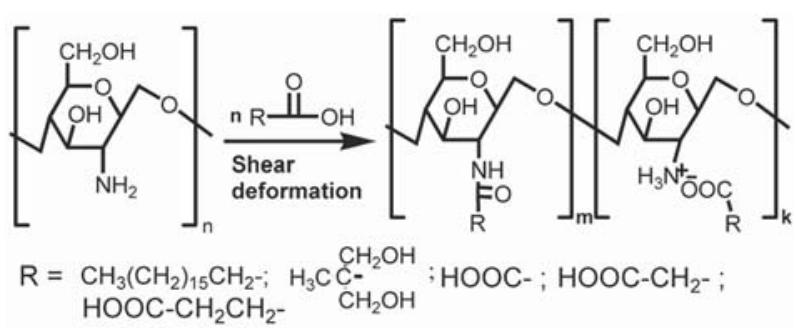

Figure 6. Solid phase synthesis of grafted derivatives of chitosan and carboxylic acids. the case of the dicarboxylic acids, they were insoluble in aqueous media, but swelled in them due to the formation of intermolecular cross-links. Chitosan modified with such higher fatty acid as stearic acid was a polymeric salt consisting of the stearate anion and the $\left[\mathrm{NH}_{3}\right]^{+}$of the repeating chitosan unit, that is, grafted polymeric salt formed. This polymeric salt was insoluble in aqueous media; this may be due to the dramatic increase of the hydrophobicity of the macromolecules. Modified derivatives based on 2,2bis-(hydroxymethyl)propionic acid were soluble in aqueous media by virtue of the presence in the grafted hydrocarbon fragment of the two hydroxyl groups and the short length of this hydrocarbon fragment. It was revealed that the acylation degree depended on the acidity constant of the carboxylic acid and the molar ratio of chitosan repeating unit/acid. It was proven in [176] that the maximal substitution degree with malonic (13\%) and 2,2-bis-(hydroxymethyl) propionic $(24 \%)$ acids was achieved at temperatures of 100 [175] or $150^{\circ} \mathrm{C}$ [176], respectively. Whilst oxalic acid formed grafted amides with a substitution degree of $20 \%$ at $50{ }^{\circ} \mathrm{C}$ [175].

Chitosan-graft-poly(glycolide) was synthesized via the modification of chitosan with glycolic acid, the simplest member of $\alpha$-hydroxyacids. For this, the films were cast from chitosan solutions in aqueous glycolic acid followed by the thermal treatment for $1 \mathrm{~h}$ at $105^{\circ} \mathrm{C}$ and then for $2 \mathrm{~h}$ at $125^{\circ} \mathrm{C}$ [177] (Figure 7).

Here, the process did not stop in the stage of the mono-acylic derivative formation, and it proceeded further with the formation of grafted oligo- and polyesters. This approach stands out in its simplicity, environmental friendliness along with the absence of toxic reagents and solvents. The films were capable to swell after the thermal treatment, and the swelling
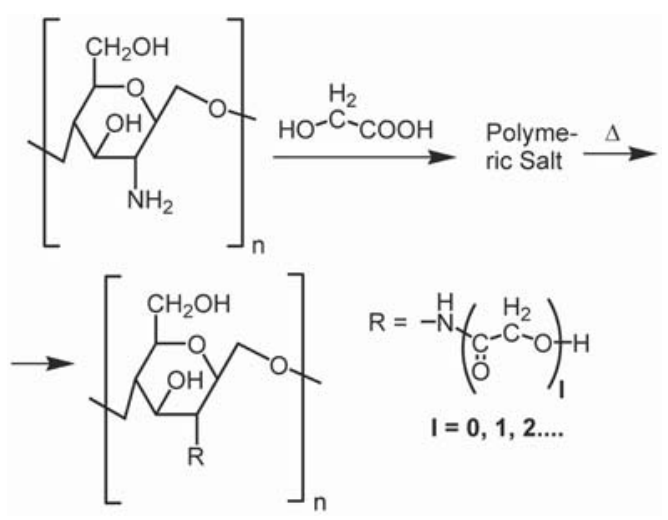

Figure 7. Modification of chitosan with glycolic acid with obtaining chitosan-graft-poly(glycolide). 
extent was proportional to the amount of grafted glycolic acid; this may be explained by the increase of the polymer matrix disorderliness. Chitosan-graftpoly(glycolides) can be utilized in medicine, biology, for example, as separation membranes. Besides, they can be used as polymer matrices for the design of the nano-hybrid materials with the nano fillers based on the $\mathrm{Pt} / \mathrm{Fe}_{3} \mathrm{O}_{4}$ [178], $\mathrm{Au} / \mathrm{Fe}_{3} \mathrm{O}_{4}$ and $\mathrm{Au}$ [179, 180] nanoparticles. These nanoparticles were confirmed to participate in the adsorption of encapsulated drugs molecules and in the adhesion of seeded stromal sells. All these make similar hybrid nanocomposites promising materials for the design of scaffolds used in regenerative medicine or in the systems used for targeted drugs delivery.

A similar approach to the chitosan modification comprising of casting a film in the first step followed by the thermal treatment of it at $80-90^{\circ} \mathrm{C}$ under a pressure of 5-10 $\mathrm{mm} \mathrm{Hg}$ was used for the synthesis of chitosan-graft-poly(lactides) as well [181] (Figure 8). The obtained graft copolymers revealed a good miscibility with the fibroblast stromal cells.

Another approach to obtaining chitosan-graft-(polylactides) in liquid phase and without the casting of films consisted in heating chitosan solution in $85 \%$ water lactic acid at $70^{\circ} \mathrm{C}$ for night [182]. The first reaction step was the formation of a soluble poly(ammonium salt) between the $\left[\mathrm{NH}_{3}\right]^{+}$of the chitosan repeating units and the lactate anions. That is, this process may also be described by Figure 8, analogous to the abovementioned case with the films. Based on this graft copolymer, the sponge materials with different pore architectures were designed for the use as the wound-healing agents.

A synthesis of chitosan/graphene nanocomposites grafted across the amide bonds was carried out via the interaction of the $\mathrm{NH}_{2}$ of the chitosan repeating units

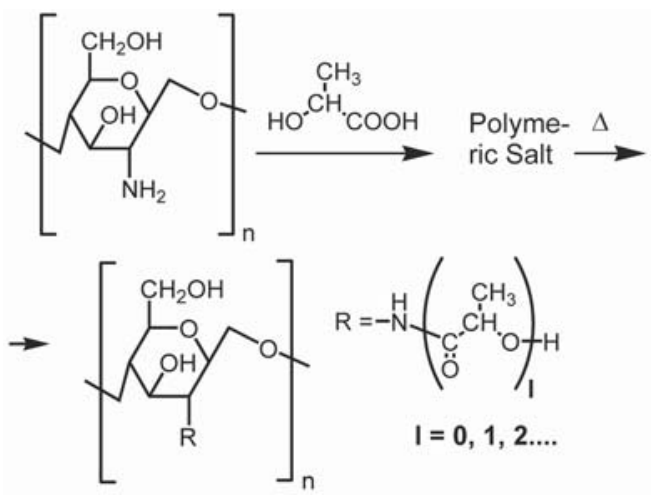

Figure 8. Modification of chitosan with lactic acid with obtaining chitosan-graft-poly(lactide). with the terminal $\mathrm{COOH}$ groups of graphene oxide (GO) in DMFA medium under ultrasonic treatment followed by the reductive elimination of the epoxy and hydroxyl groups on the basal planes of the GO nanoparticles with hydrazine hydrate [183]. These nanocomposites were readily dispersed in water solutions of $\mathrm{CH}_{3} \mathrm{COOH}$. They revealed electro-rheological properties and could be perspective as the agents for the targeted drugs delivery. These nanocomposites with excellent biocompatibility and bioactivity were utilized as both good electro-rheological material and fine nanofiller. They can be perspective for biomedical applications and for the improvement of some mechanical properties of polymers. The main disadvantage of this approach was in the use of toxic hydrazine hydrate.

\subsection{Chitosan modification with derivatives of carboxylic acids}

\subsubsection{Chitosan modification with cyclic diesters or linear polyesters of hydroxyacids}

This approach, by analogy with native carboxylic acids, requires such conditions as high temperatures and/or shearing deformations owing to the low acylating ability of alkyl esters. Moreover, specific solvents and catalysts should be utilized in case of the reactions with cyclic esters in solutions.

Analogous to the abovementioned example with native lactic acid, the reaction of chitosan with cyclic diester of lactic acid in a screw extruder at temperature range from 90 to $120^{\circ} \mathrm{C}$ did not stop on the stage of the formation of grafted amide monoester; it proceeded further with the formation of grafted polyesters [184] (Figure 9).

In general, the addition of lactone on the first stage followed by the ring opening passed across the $\mathrm{NH}_{2}$ groups by virtue of their high nucleophility.

As for the selective modification of chitosan with poly(lactides) across the primary $\mathrm{OH}$ groups, the protection of the $\mathrm{NH}_{2}$ groups was implemented via the

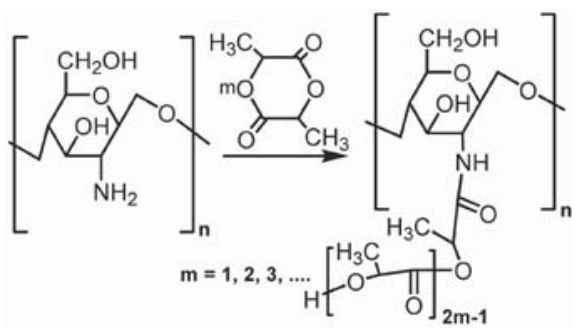

Figure 9. Modification of chitosan with cyclic diester of lactic acid with obtaining chitosan-graft-poly(lactide). 


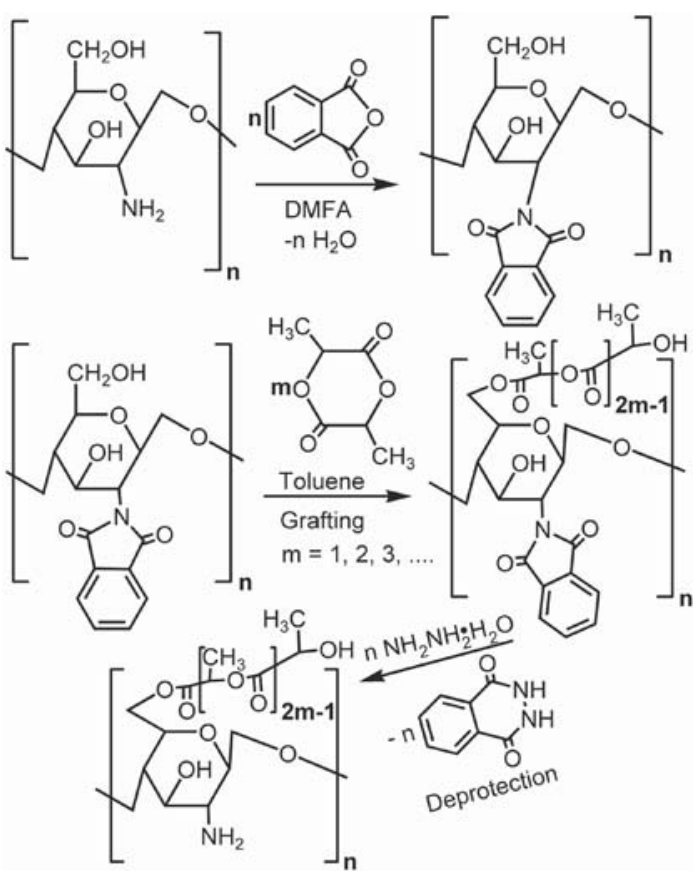

Figure 10. Selective modification of chitosan with cyclic diester of lactic acid with obtaining chitosan-graftpoly(lactide) containing free aminogroups.

imidization with phtalic anhydride in order to exclude the formation any grafted derivatives across the $\mathrm{NH}_{2}$ groups. After such a specific grafting of chitosan with poly(lactide) at $120^{\circ} \mathrm{C}$ for $60 \mathrm{~h}$, the phthalimide protecting group was easily eliminated by the treatment with hydrazine hydrate [185] (Figure 10).

An unwanted process during the de-protection stage was the partial aminolysis of the poly(lactide) chains with hydrazine hydrate, and the grafting extent after this was as low as $14 \%$. It was pointed out in the article [185] that the phthalimide residues not only played a role of the protecting groups but also were the catalysts in the reactions of the formation of the grafted poly(lactides). Chitosan-graft-poly(lactides) obtained in such a way formed stable complexes with the DNA macromolecules across the ionic interactions of the ammonium (in grafted chitosan) and phosphate (in DNA) groups. These specific chitosan-graftpoly(lactides) can be promising for the design of the biodegradable drugs carriers and the scaffold-like bio-implants. The disadvantages of this approach for obtaining such chitosan-graft-poly(lactides) were in the use of toxic organic solvents, reagents, and the multi-stage of the process.

It was proven, when chitosan underwent solid-state modification with linear poly(lactide) (Figure 11) in a screw extruder within the temperature range of 50 $150{ }^{\circ} \mathrm{C}$, that the increase of temperature favored to the reaction of poly(lactide) alcoholysis (Figure 112 );

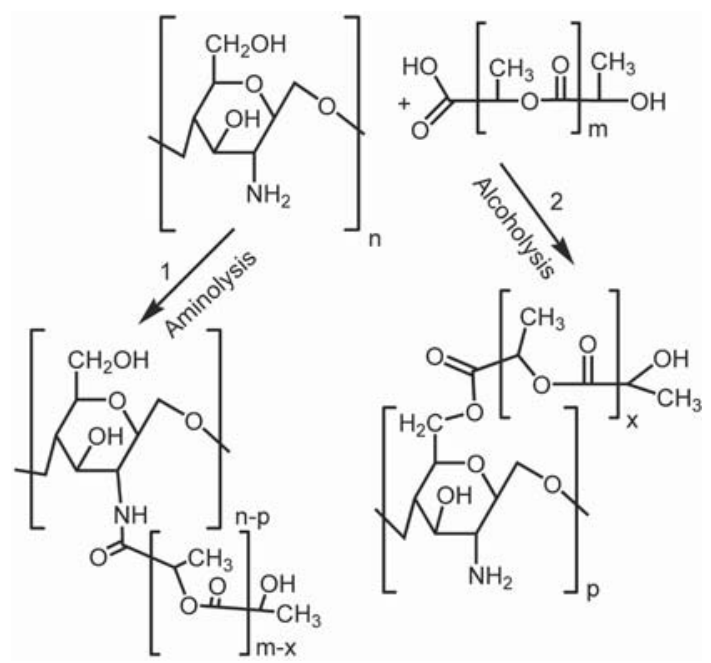

Figure 11. Modification of chitosan with linear polyester of lactic acid with obtaining chitosan-graft-poly(lactides) grafted across amide and ester bonds.

this resulted in the near uniform structure of the grafted copolymers. Lower temperatures, on contrary, favored to the predomination of aminolysis reactions (Figure 11 1). All of these processes passed with the cleavage of the ester bond of the poly(lactide) macromolecule [186].

Here, some remarks should be done. For example, Figure 11 has a tentative character because there has been a probability of a simultaneous acylation of two reaction functional groups in one repeating unit. Moreover, the kinetic reaction control may be predominant at high temperatures because the activation energy of the aminolysis reaction has to be lower than that of alcoholysis. Chitosan-graft-poly(lactides) obtained by the solid phase method can be promising for use in tissue engineering in order to design porous scaffold structures utilized in wound healing [182] and for making bone implants [187]. Besides, all similar graft copolymers contain the grafted poly (lactide) blocks, being the polymers and oligomers of lactic acid, a natural substance, which is resorbed by an organism during an implant biodegradation.

Other examples of the chitosan modification with cyclic esters of hydroxycarboxylic acids were in the use of $\varepsilon$-caprolactones. In [25], different approaches to the grafting process, including selective ones, of poly( $\varepsilon$-caprolactonic) fragments onto the chitosan macromolecule to yield chitosan-graft-poly ( $\varepsilon$-caprolactones) were described. In particular, two main approaches such as 'grafting from', where the side chain built up from the core macromolecule, and 'grafting to', where the 'ready-made' side chain grafted to the core macromolecule, were pointed out. In the case 


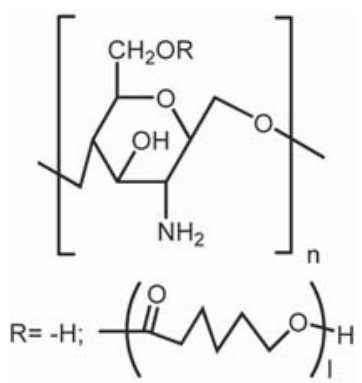

Figure 12. Chitosan-graft-poly( $\varepsilon$-caprolactone) synthesized in methanesulfonic acid medium.

of the 'grafting to' process, the size of the grafted residues was almost identical to that of the initial oligo- or macromolecules.

The specific approach to obtaining chitosan-graftpoly( $\varepsilon$-caprolactone) via the interaction of the carefully dried chitosan with $\varepsilon$-caprolactone in methanesulfonic acid medium at $45^{\circ} \mathrm{C}$ was described in [188]. The $\mathrm{CH}_{2} \mathrm{OH}$ groups participated in the process of the 'grafting from' copolymerization, and the $\mathrm{NH}_{2}$ groups did not take part in this process, probably, due to their quaternization in methanesulfonic acid medium (Figure 12).

The graft copolymer obtained was soluble in most organic solvents, and it could be used for making nano-threads by the electro-spining method. The formed nano-threads were utilized for the design of the fibrin-like mat scaffolds used for regenerating a damaged skin.

\subsubsection{Chitosan modification with carboxylic acids anhydrides}

Anhydrides of carboxylic acids are more reactive than native carboxylic acids or their alkyl esters. Hence, the grafted amides of chitosan from such carboxylic acids derivatives form under relatively mild conditions.

In order to obtain biodegradable materials compatible with blood, chitosan acylation was carried out with anhydrides of acetic, propionic, butanoic, valeric, and

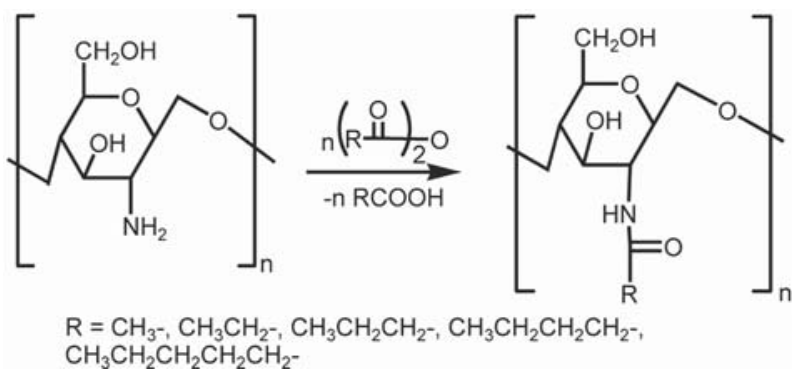

Figure 13. Chitosan acylation with anhydrides of acetic, propionic, butanoic, valeric, and hexanoic acids. hexanoic acids to yield grafted amides with the modification degree of 20-50\% [189] (Figure 13).

The blood compatibility of the acylated chitosan derivatives improved with the increase in the length of hydrocarbon residues of acids, whilst the biodegradable properties did not change in an appreciable degree. In addition, the chitosan modification with anhydrides of stearic, palmitic and octanoic acids in DMSO medium at $60^{\circ} \mathrm{C}$ for $8 \mathrm{~h}$ was implemented [190]. In this case, a modification degree of 0.9$29.6 \%$ was achieved. Such derivatives in aqueous media formed nano-micelles with the dimensions of $140-278 \mathrm{~nm}$, and the critical concentration of the micelle formation depended on $\mathrm{pH}$ of media and the concentration of $\mathrm{NaCl}$.

Unlike anhydrides, the products of the $\mathrm{OH}$ and $\mathrm{NH}_{2}$ groups acylation with an exhaustive degree of the modification were formed when chitosan was modified in the first stage of the reaction with very high reactive chloride of hexanoic acid in chloroform medium and in the presence of pyridine as the $\mathrm{HCl}$ acceptor at about -10 to $-5^{\circ} \mathrm{C}$ in an ice-salt bath for $2 \mathrm{~h}$ [191] (Figure 14).

These products exhibited good compatibility with blood. The drawbacks of this approach were in the use of instable acid chlorides, toxic chloroform and pyridine, as well as the $\mathrm{HCl}$ elimination.

Another approach to the modification of chitosan with acid chlorides consisted in the interaction of carboxymethylchitosan with 4-formylbenzoyl chloride in the presence of triethylamine as $\mathrm{HCl}$ acceptor. The grafted derivative was then utilized to connect a doxorubicin molecule with the main polymer matrix in DMSO medium [192] (Figure 15).

Here, grafted 4-formylbenzoyl amide played a role of the anchor residue in order to connect doxorubicin, which was released later in a tumor. The final products with a doxorubicin loading of 5.58-10.45\% were capable to form nano-micelles with sizes of about 114-268 nm. It was proven that the doxorubicin release behavior depended on $\mathrm{pH}$ of media, and the

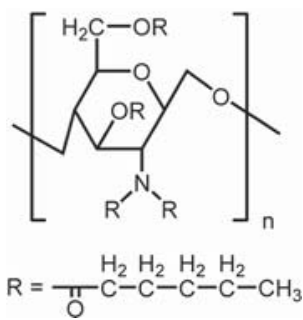

Figure 14. Chitosan exhaustively acylated with chloride of hexanoic acid. 


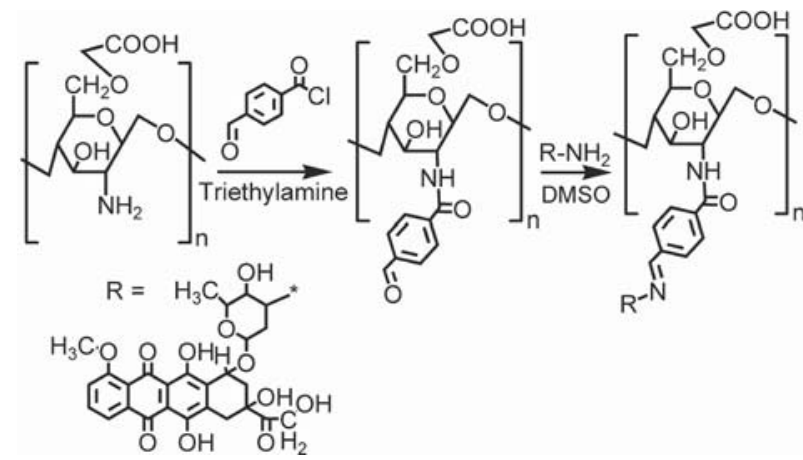

Figure 15. Interaction of carboxymethylchitosan with 4formylbenzoyl chloride followed by anchoring doxorubicin across azomethine bond.

release increased at lower $\mathrm{pH}$. The drawbacks of this approach were in the use of toxic $\mathrm{SOCl}_{2}$ for the synthesis of 4-formylbenzoyl chloride and trimethylamine.

As for the modification with linear poly(anhydrides) of dicarboxylic acids, specific examples of the chitosan interaction with poly(adipine) and poly(sebacine) anhydrides were described in [193] (Figure 16).

The modification was carried out in toluene medium (toxic and flammable solvent), and the yields the grafted poly(anhydrides) were 60.3 and $51.1 \%$ for poly(adipine) and poly(sebacine) anhydrides, respectively. Authors claimed that such derivatives could be promising as the DNA and gene materials carriers.

The chitosan acylation with cyclic anhydrides of dicarboxylic acids, for example, with maleic anhydride in DMAA medium passed across the ring opening and the selective formation of poly(amideacids) [194] (Figure 17).

Maleinated chitosan is an effective adsorbent of dyes. It can also be a promising material for regenerative medicine.

An analogous reaction followed by the ring opening and the formation of grafted poly(amideacids) is characteristic for anhydrides of succinic acids, e.g., for 3-(dodec-2-en-1-yl) succinic anhydride [195] (Figure 18).

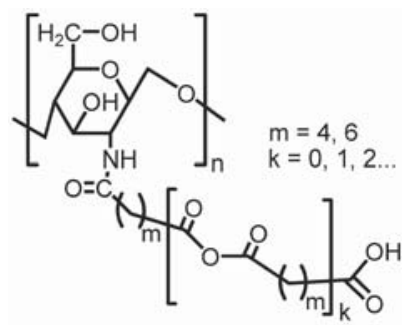

Figure 16. Chitosan modified with poly(adipine) and poly (sebacine) anhydrides.

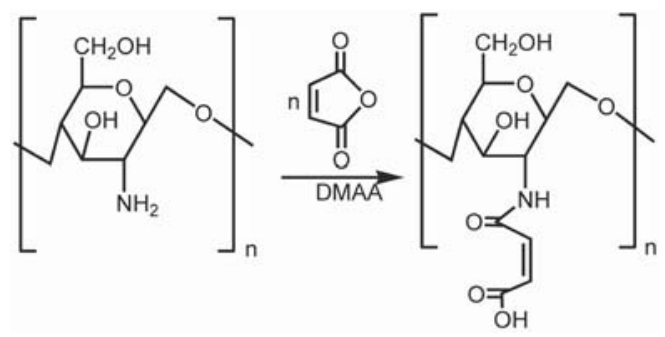

Figure 17. Chitosan modification with maleic anhydride in DMAA medium.

The reaction was implemented in a medium of the mixture of $1 \%$ water in $\mathrm{CH}_{3} \mathrm{COOH}$ and methanol ( $1 / 1$ by volume). Here, a modification degree of $5-$ $30 \%$ was achieved. These grafted derivatives of chitosan were soluble in water in the form of sodium poly (salts) and possessed surfactant properties due to the presence of the long hydrocarbon residue. Hence, they can be utilized as polymeric soaps and thickeners.

Such cyclic anhydrides as succinic, maleic, and phthalic were utilized for the solid-phase modification of chitosan. This approach was realized in the work [176] (Figure 19).

Amideacids grafted onto the core chitosan macromolecule were obtained with nearly quantitative yields by virtue of the high reactivity of five-membered cyclic anhydrides. These grafted derivatives were insoluble in acidic aqueous media and formed gel-like masses. The main advantage of such a solid phase reaction was in the absence of toxic and flammable reagents and solvents.

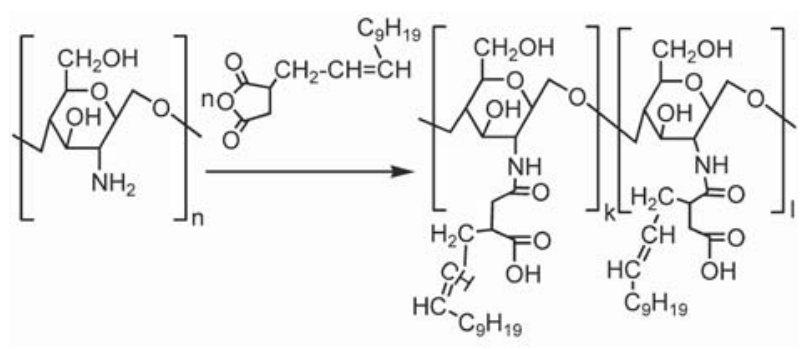

Figure 18. Chitosan modification with 3-(dodec-2-en-1-yl) succinic anhydride.

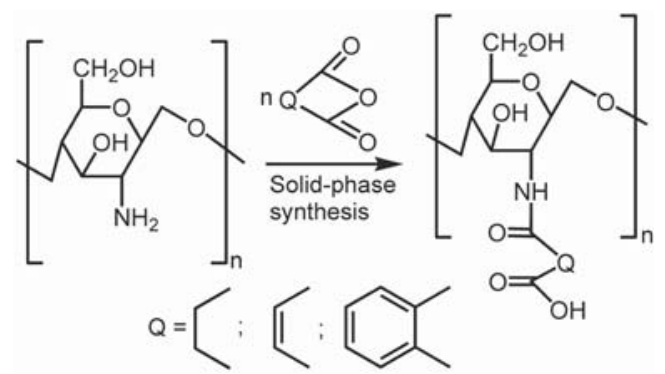

Figure 19. Solid-phase modification of chitosan with succinic, maleic and phtalic anhydrides. 


\subsubsection{Chitosan modification with 'activated' derivatives of carboxylic acids}

$N$-hydroxysuccinimide esters (so-called 'activated esters') have found wide application in the chitosan modification. Such esters, due to their stability in different media, can be utilized both in situ and separately even in protic solvents. To obtain these derivatives, such condensing reagents as mixtures of either carbodiimides with tertiary aliphatic or aromatic amines and $N$-hydroxysuccinimide or carbodiimides containing tertiary amino group, e. g., $N$-ethyl- $N^{\prime}$-(3dimethylaminopropyl)carbodiimide with $N$-hydroxysuccinimide alone were utilized.

For example, the methods for the modification of low molecular chitosans (chitosan oligomers) with highest fatty acids in the presence of such condensing systems as carbodiimide/ $N$-hydroxysuccinimide or carbodiimide/4-substituted aminopyridine were described [25, 196-201] (Figure 20). Here, an 'activated' derivative of any carboxylic acid formed in situ and then reacted with the chitosan aminogroups to yield the grafted amides.

In this case, low molecular chitosans (about 3.0 $45.0 \mathrm{kDa}$ ) were utilized, in general, and the reactions were carried out in dichloromethane, water-alcohol or water-acetone media at about $40-80^{\circ} \mathrm{C}$. The grafted derivatives obtained with a modification degree of 3.30-63.41\% formed nano-micelles in different media and could be utilized as nano-systems for the delivery of drugs or genes.

The similar approach with the use of carbodiimides was also utilized for grafting poly(lactides) onto chitosan. The essence of such an approach was in the interaction of the terminal $\mathrm{COOH}$ group of poly(lactic) acid with chitosan in DMSO medium and in the presence of a condensing system such as $N$-ethyl- $N^{\prime}-$ (dimethylaminopropyl) carbodiimide hydrochloride/ $\mathrm{N}$-hydroxysuccinimide [187] (Figure 21).

Here, the grafting, analogous to the abovementioned case, occurred predominantly across the $\mathrm{NH}_{2}$ groups.

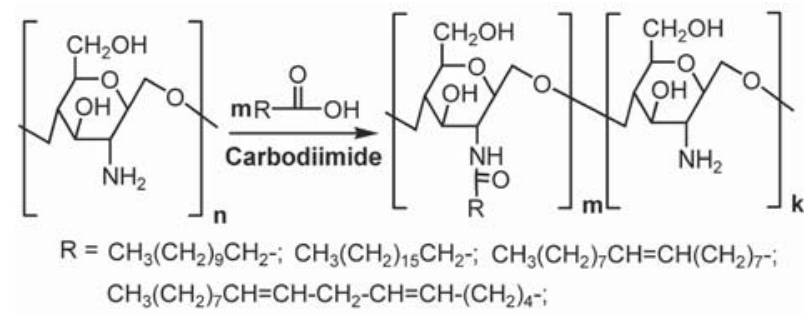

Figure 20. Chitosan modification with highest fatty acids in liquid phase and in presence of carbodiimide condensing systems.

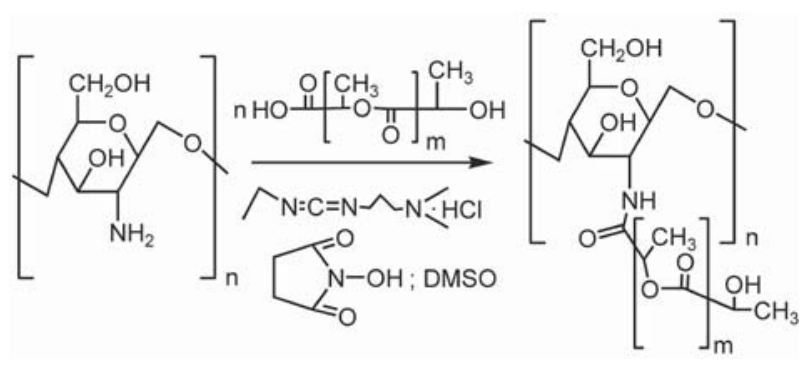

Figure 21. Chitosan 'grafting on' modification with polylactides in liquid phase and in presence of carbodiimide condensing systems.

These grafted chitosans revealed good anti-coagulant activity and blood compatibility along with the absence of cell toxicity and inflammatory processes.

An analogous grafting of poly(lactides) onto the chitosan macromolecule was also implemented in a medium of the mixture of DMFA/water solution of $\mathrm{CH}_{3} \mathrm{COOH}$ [202]. A blend of $N$-ethyl- $N$ '-(dimethylaminopropyl) carbodiimide hydrochloride with $N$-hydroxysuccinimide was utilized as the condensing system. Unlike the previous examples, a copolymer of lactide with citric acid as the cross-linker was used in order to obtain three-dimensional crosslinked polymers. The nanocapsules with dimensions of 97-164 nm were made based on these graft copolymers, which could be utilized to encapsulate such antitumor drugs as doxorubicin and temozolomide. The mixture of $N$-ethyl- $N$ '-(3-dimethylaminopropyl) carbodiimide hydrochloride together with $N$-hydroxysuccinimide was utilized in order to graft methyl glycinate to carboxymethylchitosan via amide bond formation. Then, the methyl ester groups of the glycinate residues were transformed to hydrazides via a treatment with hydrazine hydrate [203]. Such hydrazides possessed the ability to form hydrazone of daunorubicin (antitumor drug). The structure of this daunorubicin conjugate is shown on Figure 22.

These conjugates formed smart $\mathrm{pH}$-sensitive nanoparticles with mean sizes of about 104-216 nm and the maximal drug capacity of $12.45 \%$. Such nanoparticles unfolded under decreasing $\mathrm{pH}$ in a tumor cell followed by the release of daunorubicin via the azomethine bond hydrolysis. The drawback of this approach was in the use of toxic hydrazine. The use of hydrazide for the connection of the antitumor drug residue instead of azomethines from aldehyde as in [192] seemed to be due to the lesser electrophilic activity of the ketone fragment in daunorubicin.

Graphene oxide nanoparticles, due to the presence of the 'terminal' $\mathrm{COOH}$ groups, can also graft onto 


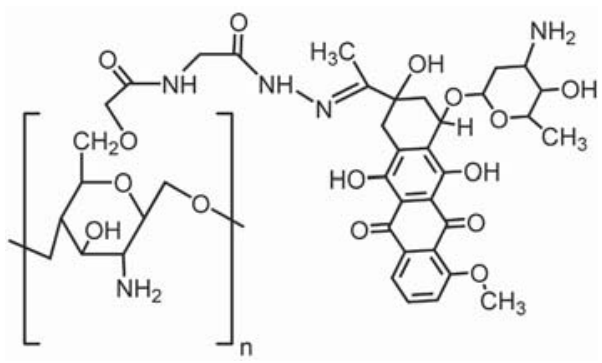

Figure 22. Daunorubicin anchored with core macromolecule across of hydrazone of grafted amide of glycine and carboxymethylchitosan.

chitosan in DMFA medium under ultrasound treatment, utilizing a condensing system such as dicyclohexylcarbodiimid/4-aminopyridine [204]. Here, the grafting passed via amide bond formation. The grafted nano-derivative formed colloid solutions in $2 \%$ water $\mathrm{CH}_{3} \mathrm{COOH}$ under the intensive ultrasound treatment. Then, these solutions were used in order to make film materials with the chitosan polymer matrix. These materials were compatible with stem cells.

Using the 'carbodiimide' approach, the fragments of deoxycholic (biliary acid with the steroid fragment) and ethylenediaminetetraacetic acids were grafted onto the chitosan macromolecule via the amide bonds formation [23]. Chitosans with the grafted deoxycholic residues formed the conjugates with DNA. Such conjugates can be promising as gene material carriers. As for chitosans with the grafted ethylenediaminetetraacetic residues, they revealed a positive synergetic effect of complexation ability that was characteristic for both the initial modifying agent and native chitosan.

$\mathrm{N}$-hydroxysuccinimide esters can be utilized as the separate reagents to graft carboxylic acids residues onto chitosan. For example, the palmitic acid residues were grafted onto glycol chitosan via interaction of it with $N$-hydroxysuccinimide ester of palmitic acid in water-ethanol mixture and in the presence of sodium bicarbonate [205]. In this case, the substitution degree of the grafted derivatives was achieved to be $5.49-20.13 \%$; it depended on the molar ratio of the initial reagents. Micelles based on these grafted derivatives were used for corneal delivery of cyclosporine, which is usually utilized in the immunosuppression therapies at transplantation.

$N$-hydroxysuccinimide esters can also be utilized to graft selectively the poly( $\varepsilon$-caprolactone) onto chitosan [206] (Figure 23). Here, the abovementioned 'grafting on' approach was used. A complex multistage synthesis of chitosan-graft-poly( $\varepsilon$-caprolactone) was implemented exclusively across the chitosan $\mathrm{NH}_{2}$ groups, where the $\mathrm{CH}_{2} \mathrm{OH}$ group was previously protected with the triphenylmethyl residue.

In this case, the poly( $\varepsilon$-caprolactone) residue connected with the 'anchor' fragment of the succinic acid residue across the ester bond. This 'anchor' fragment connected directly with the chitosan macromolecule across the amide bond. After the grafting process was stopped, the triphenylmethyl protecting group was eliminated via $\mathrm{HCl}$ treatment, regenerating

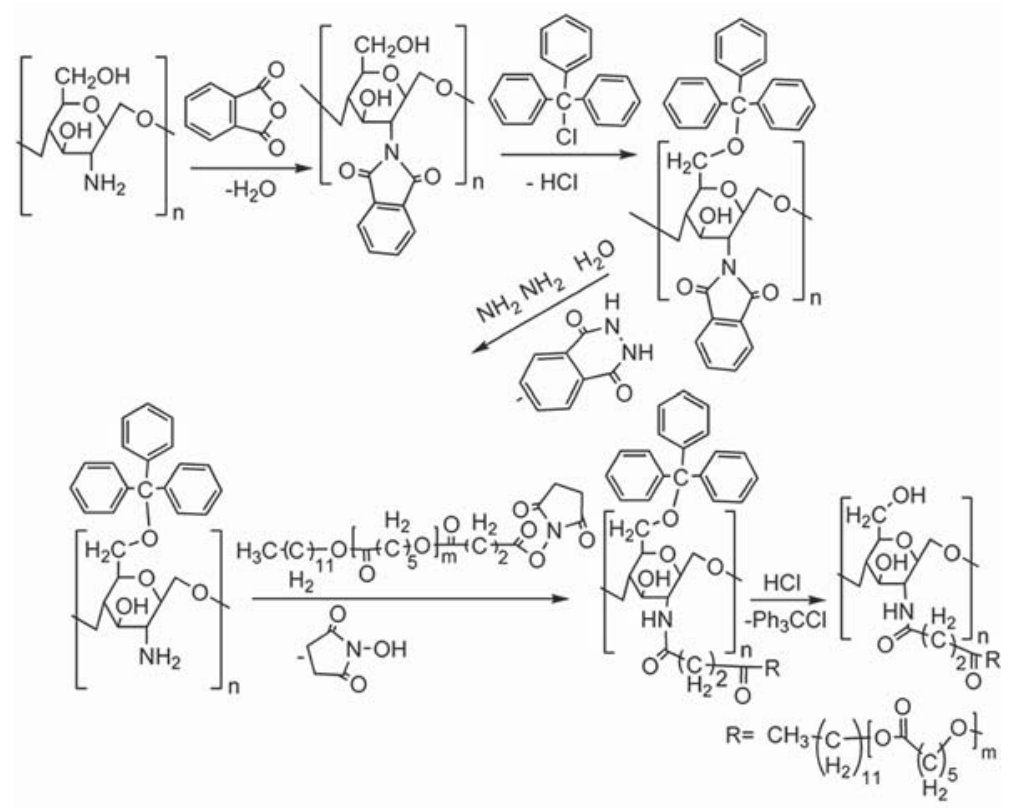

Figure 23. Selective 'grafting on' modification of chitosan with poly( $\varepsilon$-caprolactone) with obtaining chitosan-graftpoly( $\varepsilon$-caprolactone) exclusively across $\mathrm{NH}_{2}$ groups. 
the $\mathrm{CH}_{2} \mathrm{OH}$ group. These grafted chitosan derivatives were soluble in the most of organic solvents. They were capable to forming the carrier nanocapsules to deliver the drugs and the genes. The main drawbacks of this approach were in the multi-stage and the complexity of the process and utilizing toxic hydrazine hydrate for the $\mathrm{CH}_{2} \mathrm{OH}$ groups deprotection.

In addition, other specific 'activated' compounds, for example, $N$-acylazolides, dicetenes, as well as the high reactive derivatives obtained from $N$-acylated lactames (cyclic amides) and chlorinating agents can be utilized $[25,116]$. The reaction mechanisms of the acylation, utilizing such 'activated' reagents, were carefully described in [116].

\section{Conclusions}

The literature analysis has revealed that the chitosan modification with carboxylic acids can be carried out in two ways. The first was in utilizing directly either the carboxyl function or its highly reactive derivatives. The second was in the use of the active functional groups in the hydrocarbon residue, saving the carboxyl function. The $\mathrm{NH}_{2}$ (in the more extent) and/or $\mathrm{CH}_{2} \mathrm{OH}$ (in the lesser extent) groups in the chitosan macromolecule participate as the reaction centers. The examples of utilizing lower carboxylic acids or their derivatives with the number of the carbon atoms from one to six were given in the most of works. The modified products could be used in different areas of the regenerative medicine, including the design of matrix carriers of the stem cells (scaffolds).

As for such higher fatty acids as palmitic, stearic, oleic, linoleic, linolenic, and deoxycholic, low molecular chitosans (about 3.0-45.0 kDa) can be readily modified with them in the presence of the carbodiimide condensing systems. The products obtained exhibited surfactant properties, formed nano-micelles in different media, and could be utilized as nano-systems for the delivery of drugs or genes. Chitosan modified with anhydride of 3-(dodec-2-en-1-yl) succinic acid can be utilized in the form of sodium polymeric salt as a polymeric soap or a thickener.

It is necessary to note that the most of the scientific works were devoted to the preparation of the interpolymeric complexes (the conjugates), viz., chitosan/ poly(carboxylic acid). Both carbochain and heterochain poly(carboxylic acids) were utilized as the poly(acid) components. The general characteristic of all of inter-polymeric conjugates was the ability to swell; this phenomenon depended on $\mathrm{pH}$ of media. So, they could be widely utilized as the drugs carriers with controlled release.

The graft polymerization of (meth)acrylic, itaconic acids or their derivatives, vinyl esters and lactams onto chitosan was initiated with different redox systems. This approach is a scientific direction of large interest. Obtained carbochain graft copolymers, in which the side chains contain the functional groups of the initial unsaturated carboxylic acids or their derivatives, could be used as the complex-forming agents, the drugs carriers, and the components of the bone implants. It is necessary also to note the observed nowadays trend towards obtaining similar conjugates with oxidized carbon nanoparticles containing $\mathrm{COOH}$ groups.

Besides, the chitosan modification with cyclic and linear esters of such hydroxyacids as glycolic, lactic, and $\varepsilon$-hydroxycapronic ones has been widely disseminated. Grafting with these esters was carried out both in solid phase and in solution media. The main specific characteristic of them in comparison with the abovementioned carbochain graft copolymers is the good biodegradation ability. Hence, they could be utilized, in general, for the design of scaffolds and drugs carriers.

The generalization of the main approaches to the chitosan modifications with carboxylic acids and/or their derivatives is presented on Figure 24. Here, the arrows show the reaction centers that take part directly in these modification reactions.

However, despite the advantages of the grafted chitosan derivatives obtained via the interaction of this polysaccharide with carboxylic acids or their derivatives, there are some problems listed below. - The difficulties of the selective acylation of the $\mathrm{NH}_{2}$ and $\mathrm{OH}$ groups due to their different nucleophility are present. This forced researchers to use different protecting groups, which resulted in the complication of the synthetic procedures and the use of toxic reagents (e.g., hydrazine hydrate) for deprotecting the chitosan functional groups. In addition, this forced researchers to carry out the modification processes in aggressive media (e.g., in methanesulfonic acid).

- The use of toxic and flammable reagents and solvents, for example, tertiary amines, carbodiimides, chloroform, toluene, methanol, aminopyridines, etc. took place in the most of the cases (See also the previous item). 


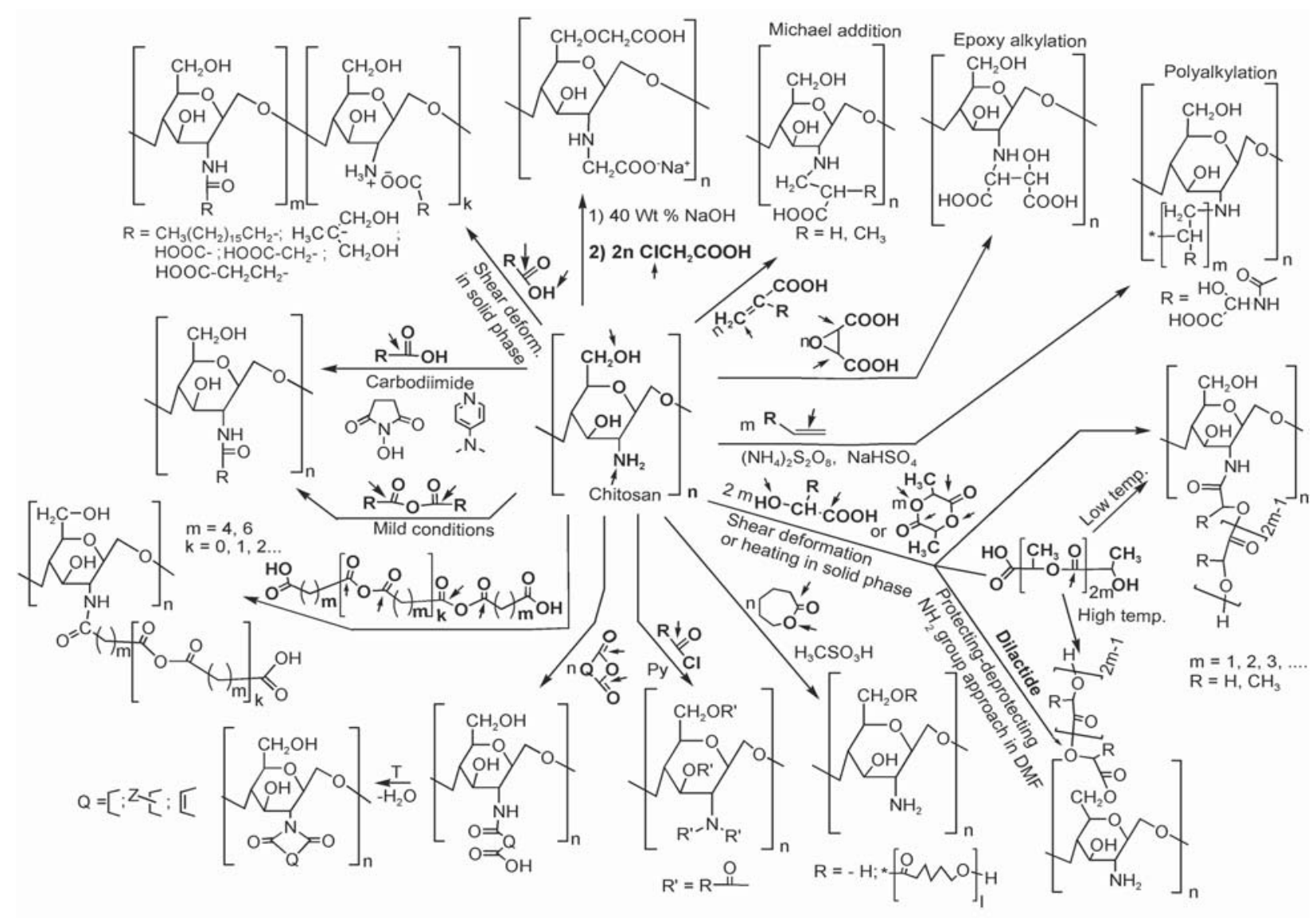

Figure 24. General scheme of main approaches to chitosan modifications with carboxylic acids and/or their derivatives.

- The environmentally safe and solid-state method for the chitosan modification was proven to be good itself only for obtaining grafted poly(lactides) from cyclic dilactides or linear poly(lactides) because the use of native (mono)carboxylic acids resulted in the derivatives with low acylation degree. Most of such acids appeared in the end-products as poly (ammoniun salts), and the use of cyclic anhydrides of dicarboxylic acids resulted in cross-linking in the most of the cases.

- In the scientific literature, the descriptions of the ways of the chitosan modification with cyclic diglycolides or linear poly(glycolides) seem to be either absent or available in limited amounts.

At the same time, the scientific efforts should be directed at searching novel ways of chitosan modification, which would be promising from the ecological and economic points of view. Hence, the main attention should be paid to perspective modification methods similar to the solid-phase ones in a screw extruder [175-177], a film [177, 181], and aqueous media without any additives [182]. In [185], the probable catalytic effect of the phthalimide residue on the 'grafting from' process of cyclic dilactide proceeding on chitosan macromolecule was mentioned. This fact can give an impulse for investigations in this direction concerning a use of phthalimides as catalysts for promoting a formation of grafted chitosan derivatives with cyclic, oligo- or polyesters of hydroxyacids. The interesting and perspective directions toward to the development of carbon, inorganic nanomaterials, and micellar nano-systems, including ones functionalized with the $\mathrm{COOH}$ groups, should also be developed $[130,131,168-173,179,180,183$, 188, 190, 192, 202-204, 206].

\section{Acknowledgements}

The review was prepared under the financial support of the Russian Science Foundation (project number: 16-15-00042).

\section{References}

[1] Kuznetsova D. S., Timashev P. S., Bagratashvili V. N., Zagaynova E. V.: Scaffold- and cell system-based bone grafts in tissue engineering (review). Sovremennye Tehnologii v Medicine, 6, 201-211 (2012).

[2] Venkatesan J., Kim S-K.: Chitosan composites for bone tissue engineering - An overview. Marine Drugs, 8, 2252-2266 (2010).

https://doi.org/10.3390/md8082252 
[3] Khor E., Lim L. Y.: Implantable applications of chitin and chitosan. Biomaterials, 24, 2339-2349 (2003). https://doi.org/10.1016/S0142-9612(03)00026-7

[4] Costa-Pinto A. R., Reis R. L., Neves N. M.: Scaffolds based bone tissue engineering: The role of chitosan. Tissue Engineering Part B: Reviews, 17, 331-347 (2011). https://doi.org/10.1089/ten.teb.2010.0704

[5] Krishna Rao K. S. V., Chung I., Ha C-S.: Synthesis and characterization of poly(acrylamidoglycolic acid) grafted onto chitosan and its polyelectrolyte complexes with hydroxyapatite. Reactive and Functional Polymers, 68, 943-953 (2008).

https://doi.org/10.1016/j.reactfunctpolym.2008.02.002

[6] Dutta P. K., Dutta J., Tripathi V. S.: Chitin and chitosan: Chemistry, properties and applications. Journal of Scientific and Industrial Research, 63, 20-31 (2004).

[7] Hamman J. H.: Chitosan based polyelectrolyte complexes as potential carrier materials in drug delivery systems. Marine Drugs, 8, 1305-1322 (2010).

https://doi.org/10.3390/md8041305

[8] Kritchenkov A. S., Andranovitš S., Skorik Y. A.: Chitosan and its derivatives: Vectors in gene therapy. Russian Chemical Reviews, 86, 231-239 (2017). https://doi.org/10.1070/RCR4636

[9] Adewuyi S., Bisiriyu I. O., Akinremi C. A.: Zinc (II) metal ion complexes of chitosan: Toward heterogeneous-active catalysts for the polymerization of vinyl acetate. Ife Journal of Science, 17, 749-754 (2015).

[10] Elmezayyen A. S., Reicha F. M.: Preparation of chitosan copper complexes: Molecular dynamic studies of chitosan and chitosan copper complexes. Open Journal of Applied Sciences, 5, 58545/1-58545/12 (2015). https://doi.org/10.4236/ojapps.2015.58041

[11] Liu H., Du Y., Wang X., Sun L.: Chitosan kills bacteria through cell membrane damage. International Journal of Food Microbiology, 95, 147-155 (2004).

https://doi.org/10.1016/j.ijfoodmicro.2004.01.022

[12] Lin W-T., Zhang Y-Y., Tan H-L., Ao H-Y., Duan Z-L., He G., Tang T-T.: Inhibited bacterial adhesion and biofilm formation on quaternized chitosan-loaded titania nanotubes with various diameters. Materials, 9, 155/1155/14 (2016).

https://doi.org/10.3390/ma9030155

[13] Lehr C-M., Bouwstra J. A., Schacht E. H., Junginger H. E.: In vitro evaluation of mucoadhesive properties of chitosan and some other natural polymers. International Journal of Pharmaceutics, 78, 43-48 (1992). https://doi.org/10.1016/0378-5173(92)90353-4

[14] Mazzarino L., Coche-Guérente L., Lemos-Senna P. L. E., Borsali R.: On the mucoadhesive properties of chitosan-coated polycaprolactone nanoparticles loaded with curcumin using quartz crystal microbalance with dissipation monitoring. Journal of Biomedical Nanotechnology, 10, 787-794 (2014).

https://doi.org/10.1166/jbn.2014.1768
[15] Mathews S., Gupta P. K., Bhonde R., Totey S.: Chitosan enhances mineralization during osteoblast differentiation of human bone marrow-derived mesenchymal stem cells, by upregulating the associated genes. Cell Proliferation, 44, 537-549 (2011). https://doi.org/10.1111/j.1365-2184.2011.00788.x

[16] Oh J., Kim K., Won S. W., Cha C., Gaharwar A. K., Selimović Š., Bae H., Lee K. H., Lee D. H., Lee S-H., Khademhosseini A.: Microfluidic fabrication of cell adhesive chitosan microtubes. Biomedical Microdevices, 15, 465-472 (2013). https://doi.org/10.1007/s10544-013-9746-z

[17] Li Y., Wang X., Wei Y., Tao L.: Chitosan-based selfhealing hydrogel for bioapplications. Chinese Chemical Letters, 28, 2053-2057 (2017). https://doi.org/10.1016/j.cclet.2017.09.004

[18] Jiang D., Zhang X., Yu D., Xiao Y., Wang T., Su Z., Liu Y., Zhang N.: Tumor-microenvironment relaxivitychangeable Gd-loaded poly(L-lysine)/carboxymethyl chitosan nanoparticles as cancer-recognizable magnetic resonance imaging contrast agents. Journal of Biomedical Nanotechnology, 13, 243-254 (2017). https://doi.org/10.1166/jbn.2017.2346

[19] Wei X., Zhang Z., Qian Z.: Pharmacokinetics and in vivo fate of drug loaded chitosan nanoparticles. Current Drug Metabolism, 13, 364-371 (2012). https://doi.org/10.2174/138920012800166580

[20] An Z-Z., Li Z., Guo Y-Y., Chen X-L., Zhang K-N., Zhang D-X., Xue Z-H., Zhou X-B., Lu X-Q.: Preparation of chitosan $/ N$-doped graphene natively grown on hierarchical porous carbon nanocomposite as a sensor platform for determination of tartrazine. Chinese Chemical Letters, 28, 1492-1498 (2017).

https://doi.org/10.1016/j.cclet.2017.02.014

[21] Duan S., Song M., He J., Zhou N., Zhou S., Zhao J., Fang Y., Peng Y., Huang X., Luo G., Lai C., Yu X., Zhang Z., Xie Y., Zhao Y., Lu X.: Folate-modified chitosan nanoparticles coated interferon-inducible protein10 gene enhance cytotoxic T lymphocytes' responses to hepatocellular carcinoma. Journal of Biomedical Nanotechnology, 12, 700-709 (2016).

https://doi.org/10.1166/jbn.2016.2216

[22] Zhu Y., Bai Z-S., Wang H-L.: Microfluidic synthesis of thiourea modified chitosan microsphere of high specific surface area for heavy metal wastewater treatment. Chinese Chemical Letters, 28, 633-641 (2017).

https://doi.org/10.1016/j.cclet.2016.10.031

[23] Jayakumar R., Prabaharan M., Reis R. L., Mano J. F.: Graft copolymerized chitosan - Present status and applications. Carbohydrate Polymers, 62, 142-158 (2005). https://doi.org/10.1016/j.carbpol.2005.07.017

[24] Alves N. M., Mano J. F.: Chitosan derivatives obtained by chemical modifications for biomedical and environmental applications. International Journal of Biological Macromolecules, 43, 401-414 (2008). https://doi.org/10.1016/j.ijbiomac.2008.09.007 
[25] Riva R., Ragelle H., des Rieux A., Duhem N., Jérême C., Préat V.: Chitosan and chitosan derivatives in drug delivery and tissue engineering. in 'Chitosan for biomaterials II.' (eds.: Jayakumar R., Prabaharan M., Muzzarelli R.), Springer, Berlin, 19-44 (2011). https://doi.org/10.1007/12_2011 137

[26] Badawy E. I. M., Rabea E. I.: A biopolymer chitosan and its derivatives as promising antimicrobial agents against plant pathogens and their applications in crop protection. International Journal of Carbohydrate Chemistry, 2011, 460381/1-460381/29 (2011).

https://doi.org/10.1155/2011/460381

[27] Rani M., Agarwal A., Negi Y. S.: Review: Chitosan based hydrogel polymeric beads - As drug delivery system. BioResources, 5, 2765-2807 (2010).

[28] Amidi M., Mastrobattista E., Jiskoot W., Hennink W. E.: Chitosan-based delivery systems for protein therapeutics and antigens. Advanced Drug Delivery Reviews, 62, 59-82 (2010). https://doi.org/10.1016/j.addr.2009.11.009

[29] Krajewska B.: Application of chitin- and chitosan-based materials for enzyme immobilizations: A review. Enzyme and Microbial Technology, 35, 126-139 (2004). https://doi.org/10.1016/j.enzmictec.2003.12.013

[30] Zakaria Z., Izzah Z., Jawaid M., Hassan A.: Effect of degree of deacetylation of chitosan on thermal stability and compatibility of chitosan-polyamide blends. BioResources, 7, 5568-5580 (2012).

[31] Yadav H. K. S., Joshi G. B., Singh M. N., Shivakumar H. G.: Naturally occurring chitosan and chitosan derivatives: A review. Current Drug Therapy, 6, 2-11 (2011). https://doi.org/10.2174/157488511794079013

[32] Patel M. P., Patel R. R., Patel J. K.: Chitosan mediated targeted drug delivery system: A review. Journal of Pharmacy and Pharmaceutical Science, 13, 536-557 (2010). https://doi.org/10.18433/J3JC7C

[33] Goy R. C., de Britto D., Assis O. B. G.: A review of the antimicrobial activity of chitosan. Polímeros, 19, 241247 (2009). https://doi.org/10.1590/S0104-14282009000300013

[34] Kumar B. N. P., Mahaboobi S., Satyam S.: Chitosan in medicine-A mini review. Journal of Molecular Pharmaceutics and Organic Process Research, 5, 134/1-134/2 (2017). https://doi.org/10.4172/2329-9053.1000134

[35] Yadu N .V. K., Raghvendrakumar M., Aswathy V., Parvathy P., Sunija S., Neelakandan M. S., Nitheesha S., Vishnu K. A.: Chitosan as promising materials for biomedical application: Review. Research and Development in Material Science, 2, 1-16 (2017). https://oi.org/10.31031/RDMS.2017.02.000543

[36] Zargar V., Asghari M., Dashti A.: A review on chitin and chitosan polymers: Structure, chemistry, solubility, derivatives, and applications. ChemBioEng Reviews, 3, 204-226 (2015). https://doi.org/10.1002/cben.201400025
[37] Usman A., Zia K. M., Zuber M., Tabasum S., Rehman S., Zia F.: Chitin and chitosan based polyurethanes: A review of recent advances and prospective biomedical applications. International Journal of Biological Macromolecules, 86, 630-645 (2016).

https://doi.org/10.1016/j.ijbiomac.2016.02.004

[38] Thomas N. V., Venkatesan J., Manivasagan P., Kim SK.: Production and biological activities of chitooligosaccharides (COS) - An overview. Journal of Chitin and Chitosan Science, 3, 1-10 (2015).

https://doi.org/10.1166/jcc.2015.1084

[39] Minami S., Okamoto Y., Saimoto H., Shigemasa Y.: Effects of chitin and its derivatives on wound-healing acceleration mechanisms. Journal of Chitin and Chitosan Science, 2, 163-178 (2014). https://doi.org/10.1166/jcc.2014.1073

[40] Semwal A., Singh R., Dutta P. K.: Chitosan: A promising substrate for pharmaceuticals. Journal of Chitin and Chitosan Science, 1, 87-102 (2013).

https://doi.org/10.1166/jcc.2013.1012

[41] Prabaharan M.: Prospects of biosensors based on chitosan matrices. Journal of Chitin and Chitosan Science, 1, 2-12 (2013). https://doi.org/10.1166/jcc.2013.1010

[42] Islam N., Ferro V.: Recent advances in chitosan-based nanoparticulate pulmonary drug delivery. Nanoscale, $\mathbf{8}$, 14341-14358 (2016). https://doi.org/10.1039/C6NR03256G

[43] Ahmed T. A., Aljaeid B. M.: Preparation, characterization, and potential application of chitosan, chitosan derivatives, and chitosan metal nanoparticles in pharmaceutical drug delivery. Drug Design, Development and Therapy, 10, 483-507 (2016). https://doi.org/10.2147/DDDT.S99651

[44] Periayah M. H., Halim A. S., Saad A. Z.: Chitosan: A promising marine polysaccharide for biomedical research. Pharmacognosy Reviews, 10, 39-42 (2016). https://doi.org/10.4103/0973-7847.176545

[45] Ravi Kumar M. N. V., Muzzarelli R. A. A., Muzzarelli C., Sashiwa H., Domb A. J.: Chitosan chemistry and pharmaceutical perspectives. Chemical Reviews, 104, 6017-6084 (2004).

https://doi.org/10.1021/cr030441b

[46] Suginta W., Khunkaewla P., Schulte A.: Electrochemical biosensor applications of polysaccharides chitin and chitosan. Chemical Reviews, 113, 5458-5479 (2013). https://doi.org/10.1021/cr300325r

[47] Jenkins D. W., Hudson S. M.: Review of vinyl graft copolymerization featuring recent advances toward controlled radical-based reactions and illustrated with chitin/ chitosan trunk polymers. Chemical Reviews, 101, 32453274 (2001).

https://doi.org/10.1021/cr000257f 
[48] Xing Y., Xu Q., Li X., Chen C., Ma L., Li S., Che Z., Lin H.: Chitosan-based coating with antimicrobial agents: Preparation, property, mechanism, and application effectiveness on fruits and vegetables. International Journal of Polymer Science, 2016, 4851730/14851730/24 (2016).

https://doi.org/10.1155/2016/4851730

[49] Rodríguez-Vázquez M., Vega-Ruiz B., Ramos-Zúñiga R., Saldaña-Koppel D. A., Quiñones-Olvera L. F.: Chitosan and its potential use as a scaffold for tissue engineering in regenerative medicine. BioMed Research International, 2015, 821279/1-821279/15 (2015). https://doi.org/10.1155/2015/821279

[50] Shirosaki Y., Hayakawa S., Osaka A., Lopes M. A., Santos J. D., Geuna S., Mauricio A. C.: Challenges for nerve repair using chitosan-siloxane hybrid porous scaffolds. BioMed Research International, 2014, 153808/1153808/7 (2014).

https://doi.org/10.1155/2014/153808

[51] Lodhi G., Kim Y-S., Hwang J-W., Kim S-K., Jeon Y-J., Je J-Y., Ahn C-B., Moon S-H., Jeon B-T., Park P-J.: Chitooligosaccharide and its derivatives: Preparation and biological applications. BioMed Research International, 2014, 654913/1-654913/13 (2014).

https://doi.org/10.1155/2014/654913

[52] Chen G., Zhao L., Qi Y., Cui Y-L.: Chitosan and its derivatives applied in harvesting microalgae for biodiesel production: An outlook. Journal of Nanomaterials, 2014, 217537/1-217537/9 (2014).

https://doi.org/10.1155/2014/217537

[53] Cumpstey I.: Chemical modification of polysaccharides. ISRN Organic Chemistry, 2013, 417672/1417672/27 (2013).

https://doi.org/10.1155/2013/417672

[54] Thakur V. K., Thakur M. K.: Recent advances in graft copolymerization and applications of chitosan: A review. ACS Sustainable Chemistry and Engineering, 2, 2637-2652 (2014). https://doi.org/10.1021/sc500634p

[55] Lanka D., Mittapally V. K.: Preparation and applications of chitosan nanoparticles: A brief review. Journal of Material Sciences, 4, r001/1-r001/5 (2016). https://doi.org/10.4172/2321-6212.1000r001

[56] Assa F., Jafarizadeh-Malmiri H., Ajamein H., Vaghari H., Anarjan N., Ahmadi O., Berenjian A.: Chitosan magnetic nanoparticles for drug delivery systems. Critical Reviews in Biotechnology, 37, 492-509 (2017). https://doi.org/10.1080/07388551.2016.1185389

[57] Malerba M., Cerana R.: Chitosan effects on plant systems. International Journal of Molecular Sciences, 17, 996/1-966/15 (2016).

https://doi.org/10.3390/ijms17070996

[58] Aduba D. C. Jr., Yang H.: Polysaccharide fabrication platforms and biocompatibility assessment as candidate wound dressing materials. Bioengineering, 4, 1/1-1/16 (2017).

https://doi.org/10.3390/bioengineering4010001
[59] Bui V. K. H., Park D., Lee Y-C.: Chitosan combined with $\mathrm{ZnO}, \mathrm{TiO}_{2}$ and $\mathrm{Ag}$ nanoparticles for antimicrobial wound healing applications: A mini review of the research trends. Polymers, 9, 21/1-21/24 (2017).

https://doi.org/10.3390/polym9010021

[60] Bhalkaran S., Wilson L. D.: Investigation of self-assembly processes for chitosan-based coagulant-flocculant systems: A mini-review. International Journal of Molecular Sciences, 17, 1662/1-1662/21 (2016). https://doi.org/10.3390/ijms17101662

[61] Bellich B., D’Agostino I., Semeraro S., Gamini A., Cesàro A.: 'The good, the bad and the ugly' of chitosans. Marine Drugs, 14, 99/1-99/31 (2016).

https://doi.org/10.3390/md14050099

[62] Pestov A., Bratskaya S.: Chitosan and its derivatives as highly efficient polymer ligands. Molecules, 21, 330/1330/35 (2016). https://doi.org/10.3390/molecules21030330

[63] Lopez-Moya F., Lopez-Llorca L. V.: Omics for investigating chitosan as an antifungal and gene modulator. Journal of Fungi, 2, 11/1-11/10 (2016). https://doi.org/10.3390/jof2010011

[64] Wang Y., Li P., Tran T. T-D., Zhang J., Kong L.: Manufacturing techniques and surface engineering of polymer based nanoparticles for targeted drug delivery to cancer. Nanomaterials, 6, 26/1-26/18 (2016). https://doi.org/10.3390/nano6020026

[65] Muzzarelli R. A. A., el Mehtedi M., Bottegoni C., Aquili A., Gigante A.: Genipin-crosslinked chitosan gels and scaffolds for tissue engineering and regeneration of cartilage and bone. Marine Drugs, 13, 73147338 (2015).

https://doi.org/10.3390/md13127068

[66] Layek B., Lipp L., Singh J.: Cell penetrating peptide conjugated chitosan for enhanced delivery of nucleic acid. International Journal of Molecular Sciences, 16, 28912-28930 (2015).

https://doi.org/10.3390/ijms161226142

[67] Cheung R. C. F., Ng T. B., Wong J. H., Chan W. Y.: Chitosan: An update on potential biomedical and pharmaceutical applications. Marine Drugs, 13, 5156-5186 (2015). https://doi.org/10.3390/md13085156

[68] Xu L., Huang Y-A., Zhu Q-J., Ye C.: Chitosan in molecularly-imprinted polymers: Current and future prospects. International Journal of Molecular Sciences, 16, 183288347 (2015). https://doi.org/10.3390/ijms160818328

[69] Ishihara M., Nguyen V. Q., Mori Y., Nakamura S., Hattori H.: Adsorption of silver nanoparticles onto different surface structures of chitin/chitosan and correlations with antimicrobial activities. International Journal of Molecular Sciences, 16, 13973-13988 (2015). https://doi.org/10.3390\%2Fijms 160613973

[70] Kerch G.: The potential of chitosan and its derivatives in prevention and treatment of age-related diseases. Marine Drugs, 13, 2158-2182 (2015). https://doi.org/10.3390/md13042158 
[71] Szymańska E., Winnicka K.: Stability of chitosan - A challenge for pharmaceutical and biomedical applications. Marine Drugs, 13, 1819-1846 (2015).

https://doi.org/10.3390/md13041819

[72] Badwan A. A., Rashid I., Al Omari M. M., Darras F. H.: Chitin and chitosan as direct compression excipients in pharmaceutical applications. Marine Drugs, 13, 1519 1547 (2015).

https://doi.org/10.3390/md13031519

[73] Azuma K., Izumi R., Osaki T., Ifuku S., Morimoto M., Saimoto H., Minami S., Okamoto Y.: Chitin, chitosan, and its derivatives for wound healing: Old and new materials. Journal of Functional Biomaterials, 6, 104-142 (2015). https://doi.org/10.3390/jfb6010104

[74] Nilsen-Nygaard J., Strand S. P., Vårum K. M., Draget K. I., Nordgård C. T.: Chitosan: Gels and interfacial properties. Polymers, 7, 552-579 (2015). https://doi.org/10.3390/polym7030552

[75] Hamed I., Özogul F., Regenstein J. M.: Industrial applications of crustacean by-products (chitin, chitosan, and chitooligosaccharides): A review. Trends in Food Science and Technology, 48, 40-50 (2016). https://doi.org/10.1016/j.tifs.2015.11.007

[76] Younes I., Rinaudo M.: Chitin and chitosan preparation from marine sources. Structure, properties and applications. Marine Drugs, 13, 1133-1174 (2015). https://doi.org/10.3390/md13031133

[77] Hozumi K., Kumai J., Yamada Y., Nomizu M.: Active peptide-conjugated chitosan matrices as an artificial basement membrane. Polymers, 7, 281-297 (2015). https://doi.org/10.3390/polym7020281

[78] Azuma K., Osaki T., Minami S., Okamoto Y.: Anticancer and anti-inflammatory properties of chitin and chitosan oligosaccharides. Journal of Functional Biomaterials, 6, 33-49 (2015). https://doi.org/10.3390/jfb6010033

[79] Kyzas G. Z., Bikiaris D. N.: Recent modifications of chitosan for adsorption applications: A critical and systematic review. Marine Drugs, 13, 312-337 (2015). https://doi.org/10.3390/md13010312

[80] Kim E., Xiong Y., Cheng Y., Wu H-C., Liu Y., Morrow B. H., Ben-Yoav H., Ghodssi R., Rubloff G. W., Shen J., Bentley W. E., Shi X., Payne G. F.: Chitosan to connect biology to electronics: Fabricating the bio-device interface and communicating across this interface. Polymers, 7, 1-46 (2015). https://doi.org/10.3390/polym7010001

[81] Wu Q-X., Lin D-Q., Yao S-J.: Design of chitosan and its water soluble derivatives-based drug carriers with polyelectrolyte complexes. Marine Drugs, 12, 62366253 (2014).

https://doi.org/10.3390/md12126236

[82] Rhee J-K., Park O. K., Lee A., Yang D. H., Park K.: Glycol chitosan-based fluorescent theranostic nanoagents for cancer therapy. Marine Drugs, 12, 6038-6057 (2014).

https://doi.org/10.3390/md12126038
[83] Aranaz I., Gutiérrez M. C., Ferrer M. L., del Monte F.: Preparation of chitosan nanocompositeswith a macroporous structure by unidirectional freezing and subsequent freeze-drying. Marine Drugs, 12, 5619-5642 (2014). https://doi.org/10.3390/md12115619

[84] Martins A. F., Facchi S. P., Follmann H. D. M., Pereira A. G. B., Rubira A. F., Muniz E. C.: Antimicrobial activity of chitosan derivatives containing $\mathrm{N}$-quaternized moieties in its backbone: A review. International Journal of Molecular Sciences, 15, 20800-20832 (2014). https://doi.org/10.3390/ijms151120800

[85] Agirre M., Zarate J., Ojeda E., Puras G., Desbrieres J., Pedraz J. L.: Low molecular weight chitosan (LMWC)based polyplexes for pDNA delivery: From bench to bedside. Polymers, 6, 1727-1755 (2014). https://doi.org/10.3390/polym6061727

[86] Solov'eva T., Davydova V., Krasikova I., Yermak I.: Marine compounds with therapeutic potential in gramnegative sepsis. Marine Drugs, 11, 2216-2229 (2013). https://doi.org/10.3390/md11062216

[87] Raftery R., O’Brien F. J., Cryan S-A.: Chitosan for gene delivery and orthopedic tissue engineering applications. Molecules, 18, 5611-5647 (2013). https://doi.org/10.3390/molecules 18055611

[88] Vázquez J. A., Rodríguez-Amado I., Montemayor M. I., Fraguas J., del Pilar González M., Murado M. A.: Chondroitin sulfate, hyaluronic acid and chitin/chitosan production using marine waste sources: Characteristics, applications and eco-friendly processes: A review. Marine Drugs, 11, 747-774 (2013).

https://doi.org/10.3390/md11030747

[89] Rodrigues S., Dionísio M., López C. R., Grenha A.: Biocompatibility of chitosan carriers with application in drug delivery. Journal of Functional Biomaterials, 3, 615-641 (2012).

https://doi.org/10.3390/jfb3030615

[90] Kumirska J., Weinhold M. X., Thöming J., Stepnowski P.: Biomedical activity of chitin/chitosan based materials - Influence of physicochemical properties apart from molecular weight and degree of $N$-acetylation. Polymers, 3, 1875-1901 (2011).

https://doi.org/10.3390/polym3041875

[91] Muzzarelli R. A. A.: Biomedical exploitation of chitin and chitosan via mechano-chemical disassembly, electrospinning, dissolution in imidazolium ionic liquids, and supercritical drying. Marine Drugs, 9, 1510-1533 (2011). https://doi.org/10.3390/md9091510

[92] Iwasaki N., Kasahara Y., Yamane S., Igarashi T., Minami A., Nisimura S-I.: Chitosan-based hyaluronic acid hybrid polymer fibers as a scaffold biomaterial for cartilage tissue engineering. Polymers, 3, 100-113 (2011). https://doi.org/10.3390/polym3010100

[93] Pangestuti R., Kim S-K.: Neuroprotective properties of chitosan and its derivatives. Marine Drugs, 8, 2117 2128 (2010). https://doi.org/10.3390/md8072117 
[94] Zhang J., Xia W., Liu P., Cheng Q., Tahi T., Gu W., Li B.: Chitosan modification and pharmaceutical/biomedical applications. Marine Drugs, 8, 1962-1987 (2010).

https://doi.org/10.3390/md8071962

[95] da Sacco L., Masotti A.: Chitin and chitosan as multipurpose natural polymers for groundwater arsenic removal and $\mathrm{As}_{2} \mathrm{O}_{3}$ delivery in tumor therapy. Marine Drugs, 8, 1518-1525 (2010).

https://doi.org/10.3390/md8051518

[96] Pillai C. K. S., Paul W., Sharma C. P.: Chitin and chitosan polymers: Chemistry, solubility and fiber formation. Progress in Polymer Science, 34, 641-678 (2009).

https://doi.org/10.1016/j.progpolymsci.2009.04.001

[97] Keong L. C., Halim A. S.: In vitro models in biocompatibility assessment for biomedical-grade chitosan derivatives in wound management. International Journal of Molecular Sciences, 10, 1300-1313 (2009). https://doi.org/10.3390/ijms10031300

[98] González-Henríquez C. M., Sarabia-Vallejos M. A., Rodriguez-Hernandez J.: Advances in the fabrication of antimicrobial hydrogels for biomedical applications. Materials, 10, 232/1-232/23 (2017).

https://doi.org/10.3390/ma10030232

[99] Sampath U. G. T., Ching Y. C., Chuah C. H., Sabariah J. J., Lin P-C.: Fabrication of porous materials from natural/synthetic biopolymers and their composites. Materials, 9, 991/1-991/32 (2016). https://doi.org/10.3390/ma9120991

[100] Chaudhari A. A., Vig K., Baganizi D. R., Sahu R., Dixit S., Dennis V., Singh S. R., Pillai S. R.: Future prospects for scaffolding methods and biomaterials in skin tissue engineering: A review. International Journal of Molecular Sciences, 17, 1974/1-1974/31 (2016). https://doi.org/10.3390/ijms17121974

[101] Khan A., Abas Z., Kim H. S., Kim J.: Recent progress on cellulose-based electro-active paper, its hybrid nanocomposites and applications. Sensors, 16, 1172/11172/30 (2016).

https://doi.org/10.3390/s16081172

[102] Ruocco N., Costantini S., Guariniello S., Costantini M.: Polysaccharides from the marine environment with pharmacological, cosmeceutical and nutraceutical potential. Molecules, 21, 551/1-551/16 (2016). https://doi.org/10.3390/molecules21050551

[103] Kadokawa J-I.: Precision synthesis of functional polysaccharide materials by phosphorylase-catalyzed enzymatic reactions. Polymers, 8, 138/1-138/20 (2016). https://doi.org/10.3390/polym8040138

[104] Wang J., Vermerris W.: Antimicrobial nanomaterials derived from natural products - A review. Materials, 9, 255/1-255/19 (2016). https://doi.org/10.3390/ma9040255
[105] Virlan M. J. R., Miricescu D., Radulescu R., Sabliov C. M., Totan A., Calenic B., Greabu M.: Organic nanomaterials and their applications in the treatment of oral diseases. Molecules, 21, 207/1-207/23 (2016). https://doi.org/10.3390/molecules21020207

[106] Cardoso M. J., Costa R. R., Mano J. F.: Marine origin polysaccharides in drug delivery systems. Marine Drugs, 14, 34/1-34/27 (2016).

https://doi.org/10.3390/md14020034

[107] Ndeboko B., Lemamy G. J., Nielsen P. E., Cova L.: Therapeutic potential of cell penetrating peptides (CPPs) and cationic polymers for chronic hepatitis B. International Journal of Molecular Sciences, 16, 28230-28241 (2015). https://doi.org/10.3390/ijms161226094

[108] Ji J., Torrealba D., Ruyra À., Roher N.: Nanodelivery systems as new tools for immunostimulant or vaccine administration: Targeting the fish immune system. Biology, 4, 664-696 (2015).

https://doi.org/10.3390/biology4040664

[109] Ohkawa K.: Nanofibers of cellulose and its derivatives fabricated using direct electrospinning. Molecules, 20, 9139-9154 (2015). https://doi.org/10.3390/molecules20059139

[110] Posocco B., Dreussi E., de Santa J., Toffoli G., Abrami M., Musiani F., Grassi M., Farra R., Tonon F., Grassi G., Dapas B.: Polysaccharides for the delivery of antitumor drugs. Materials, 8, 2569-2615 (2015). https://doi.org/10.3390/ma8052569

[111] Terzopoulou Z., Kyzas G. Z., Bikiaris D. N.: Recent advances in nanocomposite materials of graphene derivatives with polysaccharides. Materials, 8, 652-683 (2015). https://doi.org/10.3390/ma8020652

[112] Díez-Pascual A. M., Shuttleworth P. S.: Layer-bylayer assembly of biopolyelectrolytes onto thermo/ pH-responsive micro/nano-gels. Materials, 7, 74727512 (2014). https://doi.org/10.3390/ma7117472

[113] Muzzarelli R. A. A., el Mehtedi M., Mattioli-Belmonte M.: Emerging biomedical applications of nanochitins and nano-chitosans obtained via advanced ecofriendly technologies from marine resources. Marine Drugs, 12, 5468-5502 (2014). https://doi.org/10.3390/md12115468

[114] Jung W-J., Park R-D.: Bioproduction of chitooligosaccharides: Present and perspectives. Marine Drugs, 12, 5328-5356 (2014). https://doi.org/10.3390/md12115328

[115] Sharp R. G.: A review of the applications of chitin and its derivatives in agriculture to modify plant-microbial interactions and improve crop yields. Agronomy, 3, 757-793 (2013).

https://doi.org/10.3390/agronomy3040757 
[116] el Seoud O. A., Nawaz H., Arêas E. P. G.: Chemistry and applications of polysaccharide solutions in strong electrolytes/dipolar aprotic solvents: An overview. Molecules, 18, 1270-1313 (2013).

https://doi.org/10.3390/molecules 18011270

[117] Nitta S. K., Numata K.: Biopolymer-based nanoparticles for drug/gene delivery and tissue engineering. International Journal of Molecular Sciences, 14, 1629 1654 (2013).

https://doi.org/10.3390/ijms14011629

[118] Lee C-Y., Chang C-L., Wang Y-N., Fu L-M.: Microfluidic mixing: A review. International Journal of Molecular Sciences, 12, 1936-3287 (2011).

https://doi.org/10.3390/ijms12053263

[119] Park B. K., Kim M-M.: Applications of chitin and its derivatives in biological medicine. International Journal of Molecular Sciences, 11, 5152-5164 (2010). https://doi.org/10.3390/ijms11125152

[120] Khoushab F., Yamabhai M.: Chitin research revisited. Marine Drugs, 8, 1988-2012 (2010). https://doi.org/10.3390/md8071988

[121] Aam B. B., Heggset E. B., Norberg A. L., Sørlie M., Vårum K. M., Eijsink V. G. H.: Production of chitooligosaccharides and their potential applications in medicine. Marine Drugs, 8, 1482-1517 (2010). https://doi.org/10.3390\%2Fmd8051482

[122] Muzzarelli R. A. A.: Chitins and chitosans as immunoadjuvants and non-allergenic drug carriers. Marine Drugs, 8, 292-312 (2010). https://doi.org/10.3390/md8020292

[123] d'Ayala G. G., Malinconico M., Laurienzo P.: Marine derived polysaccharides for biomedical applications: Chemical modification approaches. Molecules, 13, 2069-2106 (2008).

https://doi.org/10.3390/molecules13092069

[124] Collins M. N., Birkinshaw C.: Hyaluronic acid based scaffolds for tissue engineering - A review. Carbohydrate Polymers, 92, 1262-1279 (2013).

https://doi.org/10.1016/j.carbpol.2012.10.028

[125] Fu S., Xia J., Wu J.: Functional chitosan nanoparticles in cancer treatment. Journal of Biomedical Nanotechnology, 12, 1585-1603 (2016).

https://doi.org/10.1166/jbn.2016.2228

[126] Roth P. J., Theato P.: Polymer analogous reactions. in 'Reference module in materials science and materials engineering' (ed.: Hashmi S.) Elsevier, Dublin, 1-16 (2016).

https://doi.org/10.1016/B978-0-12-803581-8.01420-X

[127] Feddersen R. L., Thorp S. N.: Sodium carboxymethylcellulose. in 'Industrial gums' (eds.: Whistler R. L., Bemiller J. N.) Academic Press, Cambridge, 537-578 (1993).

https://doi.org/10.1016/B978-0-08-092654-4.50024-3

[128] Du J., Hsieh Y-L.: Nanofibrous membranes from aqueous electrospinning of carboxymethyl chitosan. Nanotechnology, 19, 125707/1-125707/??? (2008). https://doi.org/10.1088/0957-4484/19/12/125707
[129] Sun K., Li Z. H.: Preparations, properties and applications of chitosan based nanofibers fabricated by electrospinning. Express Polymer Letters, 5, 342-361 (2011). https://doi.org/10.3144/expresspolymlett.2011.34

[130] Xie M., Liu H-H., Chen P., Zhang Z-L., Wang X-H., Xie Z-X., Du Y-M., Pan B-Q., Pang D-W.: CdSe/ZnSlabeled carboxymethyl chitosan as a bioprobe for live cell imaging. Chemical Communications, 2005, 5518-5520 (2005). https://doi.org/10.1039/B509781A

[131] Shen J-M., Tang W-J., Zhang X-L., Chen T., Zhang H-X.: A novel carboxymethyl chitosan-based folate/ $\mathrm{Fe}_{3} \mathrm{O}_{4} / \mathrm{CdTe}$ nanoparticle for targeted drug delivery and cell imaging. Carbohydrate Polymers, 88, 239249 (2012).

https://doi.org/10.1016/j.carbpol.2011.11.087

[132] Wu S-P., Dai X-Z., Kan J-R., Shilong F-D., Zhu M-Y.: Fabrication of carboxymethyl chitosan-hemicellulose resin for adsorptive removal of heavy metals from wastewater. Chinese Chemical Letters, 28, 625-632 (2017). https://doi.org/10.1016/j.cclet.2016.11.015

[133] Qi X., Qin J., Fan Y., Qin X., Jiang Y., Wu Z.: Carboxymethyl chitosan-modified polyamidoamine dendrimer enables progressive drug targeting of tumors via $\mathrm{pH}$-sensitive charge inversion. Journal of Biomedical Nanotechnology, 12, 667-678 (2016). https://doi.org/10.1166/jbn.2016.2206

[134] Li Z., Zhang L., Zeng Q.: pH-sensitivity of $N$-carboxyethyl chitosan hydrogel and drug controlled release in vitro. Materials Science Forum, 561-565, 1455-458 (2007).

https://doi.org/10.4028/www.scientific.net/MSF.561$\underline{565.1455}$

[135] Maleki A., Pajootan E., Hayati B.: Ethyl acrylate grafted chitosan for heavy metal removal from wastewater: Equilibrium, kinetic and thermodynamic studies. Journal of the Taiwan Institute of Chemical Engineers, 51, 127-134 (2015).

https://doi.org/10.1016/j.jtice.2015.01.004

[136] Abrahams J., Chen W.: Composition and method for vascular embolization. U.S. Patent 20070031467A1, USA (2007).

[137] Gruber J. V.: Process for derivatizing polyglucosamines. U.S. Patent 5621088A, USA (1997).

[138] Gruber J. V.: Oxirane carboxylic acid derivatives of polyglucosamines. U.S. Patent 5597811A, USA (1997).

[139] Xie W., Xu P., Liu Q., Xue J.: Graft-copolymerization of methylacrylic acid onto hydroxypropyl chitosan. Polymer Bulletin, 49, 47-54 (2002). https://doi.org/10.1007/s00289-002-0076-1

[140] Sun T., Xu P., Liu Q., Xue J., Xie W.: Graft copolymerization of methacrylic acid onto carboxymethyl chitosan. European Polymer Journal, 39, 189-192 (2003). https://doi.org/10.1016/S0014-3057(02)00174-X 
[141] Sun T., Xie W., Xu P.: Superoxide anion scavenging activity of graft chitosan derivatives. Carbohydrate Polymers, 58, 379-382 (2004).

https://doi.org/10.1016/j.carbpol.2004.06.042

[142] Retuert J., Yazdani-Pedram M.: Cocatalyst effect in potassium persulfate initiated grafting onto chitosan. Polymer Bulletin, 31, 559-562 (1993).

https://doi.org/10.1007/BF00297892

[143] Yazdani-Pedram M., Lagos A., Retuert J., Guerrero R., Riquelme P.: On the modification of chitosan through grafting. Journal of Macromolecular Science Part A: Pure and Applied Chemistry, 32, 1037-1047 (1995). https://doi.org/10.1080/10601329508009346

[144] Don T-M., King C-F., Chiu W-Y.: Synthesis and properties of chitosan-modified poly(vinyl acetate). Journal of Applied Polymer Science, 86, 3057-3063 (2002). https://doi.org/10.1002/app.11329

[145] Bashir S., Teo Y. Y., Ramesh S., Ramesh K.: Synthesis, characterization, properties of $N$-succinyl chitosan- $g$ poly (methacrylic acid) hydrogels and in vitro release of theophylline. Polymer, 92, 36-49 (2016). https://doi.org/10.1016/j.polymer.2016.03.045

[146] Yazdani-Pedram M., Lagos A., Jaime Retuert P.: Study of the effect of reaction variables on grafting of polyacrylamide onto chitosan. Polymer Bulletin, 48, 93-98 (2002).

https://doi.org/10.1007/s00289-002-0006-2

[147] Kyzas G. Z., Siafaka P. I., Lambropoulou D., Lazaridis N. K., Bikiaris D. N.: Poly(itaconic acid)-grafted chitosan adsorbents with different cross-linking for $\mathrm{Pb}(\mathrm{II})$ and Cd(II) uptake. Langmuir, 30, 120-131 (2014). https://doi.org/10.1021/la402778x

[148] Dergunov S. A., Nam I. K., Maimakov T. P., Nurkeeva Z. S, Shaikhutdinov E. M., Mun G. A.: Study on radiation-induced grafting of hydrophilic monomers onto chitosan. Journal of Applied Polymer Science, 110, 558-563 (2008).

https://doi.org/10.1002/app.28618

[149] Krayukhina M. A., Samoilova N. A., Erofeev A. S., Yamskov I.: Complexation of chitosan with maleic acid copolymers. Polymer Science Series A, 52, 243250 (2010).

https://doi.org/10.1134/S0965545X10030041

[150] de la Torre P. M., Torrado S., Torrado S.: Interpolymer complexes of poly(acrylic acid) and chitosan: Influence of the ionic hydrogel-forming medium. Biomaterials, 24, 1459-1468 (2003).

https://doi.org/10.1016/S0142-9612(02)00541-0

[151] Gómez-Burgaz M., García-Ochoa B., Torrado-Santiago S.: Chitosan-carboxymethylcellulose interpolymer complexes for gastric-specific delivery of clarithromycin. International Journal of Pharmaceutics, 359, 135-143 (2008).

https://doi.org/10.1016/j.ijpharm.2008.03.042
[152] Park S-H., Chun M-K., Choi H-K.: Preparation of an extended-release matrix tablet using chitosan/Carbopol interpolymer complex. International Journal of Pharmaceutics, 347, 39-44 (2008).

https://doi.org/10.1016/j.ijpharm.2007.06.024

[153] Yan L., Qian F., Zhu Q.: Interpolymer complex polyampholytic hydrogel of chitosan and carboxymethyl cellulose (CMC): Synthesis and ion effect. Polymer International, 50, 1370-1374 (2001).

https://doi.org/10.1002/pi.791

[154] Kaur A., Kaur G.: Mucoadhesive buccal patches based on interpolymer complexes of chitosan-pectin for delivery of carvedilol. Saudi Pharmaceutical Journal, 20, 21-27 (2012).

https://doi.org/10.1016\%2Fj.jsps.2011.04.005

[155] Peniche C., Elvira C., Roman J. S.: Interpolymer complexes of chitosan and polymethacrylic derivatives of salicylic acid: Preparation, characterization and modification by thermal treatment. Polymer, 39, 65496554 (1998).

https://doi.org/10.1016/S0032-3861(98)00059-7

[156] Suvorova A. I., Tyukova I. S., Borisova T. S., Pletneva L. V.: Sorption of water vapor by chitosan-carboxymethylcellulose interpolyelectrolyte complexes prepared from solutions. Vysokomolekularnye Soedineniya Series A, 47, 1265-1270 (2005).

[157] Kaur G., Jain S., Tiwary A. K.: Chitosan-carboxymethyl tamarind kernel powder interpolymer complexation: Investigations for colon drug delivery. Scientia Pharmaceutica, 78, 57-78 (2010).

https://doi.org/10.3797/scipharm.0908-10

[158] Ageev E. P., Vikhoreva G. A., Gal'braikh L. S., Matushkina N. N., Chaika E. M., Jaminsky I. V.: Preparation and properties of films based on chitosan and polyelectrolyte complexes of chitosan with carboxymethylchitin. Vysokomolekularnye Soedineniya Series A, 40, 757-762 (1998).

[159] Tekie F. S. M., Kiani M., Zakerian A., Pilevarian F., Assali A., Soleimani M., Dinarvand R., Arefian E., Atashi A., Amini M., Atyabi F.: Nano polyelectrolyte complexes of carboxymethyl dextran and chitosan to improve chitosan-mediated delivery of miR-145. Carbohydrate Polymers, 159, 66-175 (2017).

https://doi.org/10.1016/j.carbpol.2016.11.067

[160] Nikolaeva O., Budtova T., Brestkin Y., Zoolshoev Z., Frenkel S.: Rheological properties of an interpolymer complex formed between poly(acrylic acid) and methyl cellulose. Journal of Applied Polymer Science, 72, 1523-1528 (1999).

https://doi.org/10.1002/(SICI)10974628(19990620)72:12<1523::AID-APP3>3.0.CO;2-E

[161] Lee M-H., Chun M-K., Choi H-K.: Preparation of carbopol/chitosan interpolymer complex as a controlled release tablet matrix; Effect of complex formation medium on drug release characteristics. Archives of Pharmacal Research, 31, 932-937 (2008). https://doi.org/10.1007/s12272-001-1249-7 
[162] Papadimitriou S. A., Achilias D. S., Bikiaris D. N.: Chitosan- $g$-PEG nanoparticles ionically crosslinked with poly(glutamic acid) and tripolyphosphate as protein delivery systems. International Journal of Pharmaceutics, 430, 318-327 (2012).

https://doi.org/10.1016/j.ijpharm.2012.04.004

[163] Tang D-W., Yu S-H., Ho Y-C., Mi F-L., Kuo P-L., Sung H-W.: Heparinized chitosan/poly( $\gamma$-glutamic acid $)$ nanoparticles for multi-functional delivery of fibroblast growth factor and heparin. Biomaterials, 31, 9320 9332 (2010).

https://doi.org/10.1016/j.biomaterials.2010.08.058

[164] Tsao C. T., Chang C. H., Lin Y. Y., Wu M. F., Wang J. L., Young T. H., Han J. L., Hsieh K. H.: Evaluation of chitosan $/ \gamma$-poly(glutamic acid) polyelectrolyte complex for wound dressing materials. Carbohydrate Polymers, 84, 812-819 (2011).

https://doi.org/10.1016/j.carbpol.2010.04.034

[165] Keresztessy Zs., Bodnár M., Ber E., Hajdu I., Zhang M., Hartmann J. F., Minko T., Borbély J.: Self-assembling chitosan/poly- $\gamma$-glutamic acid nanoparticles for targeted drug delivery. Colloid and Polymer Science, 287, 759-765 (2009).

https://doi.org/10.1007/s00396-009-2022-3

[166] Peng S-F., Yang M-J., Su C-J., Chen H-L., Lee P-W., Wei M-C., Sung H-W.: Effects of incorporation of poly $(\gamma$-glutamic acid) in chitosan/DNA complex nanoparticles on cellular uptake and transfection efficiency. Biomaterials, 30, 1797-1808 (2009). https://doi.org/10.1016/j.biomaterials.2008.12.019

[167] Lin Y-H., Chung C-K., Chen C-T., Liang H-F., Chen S-C., Sung H-W.: Preparation of nanoparticles composed of chitosan/poly- $\gamma$-glutamic acid and evaluation of their permeability through caco- 2 cells. Biomacromolecules, 6, 1104-1112 (2005).

https://doi.org/10.1021/bm049312a

[168] Li X., Feng J., Zhang R., Wang J., Su T., Tian Z., Han D., Zhao C., Fan M., Li C., Liu B., Feng X., Nie Y., Wu K., Chen Y., Deng H., Cao F.: Quaternized chitosan/alginate- $\mathrm{Fe}_{3} \mathrm{O}_{4}$ magnetic nanoparticles enhance the chemosensitization of multidrug-resistant gastric carcinoma by regulating cell autophagy activity in mice. Journal of Biomedical Nanotechnology, 12, 948 961 (2016).

https://doi.org/10.1166/jbn.2016.2232

[169] Pan Y., Wu T., Bao H., Li L.: Green fabrication of chitosan films reinforced with parallel aligned graphene oxide. Carbohydrate Polymers, 83, 1908-1915 (2011). https://doi.org/10.1016/j.carbpol.2010.10.054

[170] Wang S-F., Shen L., Zhang W-D., Tong Y-J.: Preparation and mechanical properties of chitosan/carbon nanotubes composites. Biomacromolecules, 6, 3067 3072 (2005).

https://doi.org/10.1021/bm050378v

[171] Yang X., Tu Y., Li L., Shang S., Tao X-M.: Well-dispersed chitosan/graphene oxide nanocomposites. ACS Applied Materials and Interfaces, 2, 1707-1713 (2010). https://doi.org/10.1021/am100222m
[172] Delavar Z., Shojaei A.: Enhanced mechanical properties of chitosan/nanodiamond composites by improving interphase using thermal oxidation of nanodiamond. Carbohydrate Polymers, 167, 219-228 (2017). https://doi.org/10.1016/j.carbpol.2017.03.048

[173] Cobos M., González B., Fernández M. J., Fernández M. D.: Chitosan-graphene oxide nanocomposites: Effect of graphene oxide nanosheets and glycerol plasticizer on thermal and mechanical properties. Journal of Applied Polymer Science, 134, 45092/1-45092/??? (2017). https://doi.org/10.1002/app.45092

[174] Hu K., Kulkarni D. D., Choi I., Tsukruk V. V.: Graphene-polymer nanocomposites for structural and functional applications. Progress in Polymer Science, 39, 1934-1972 (2014). https://doi.org/10.1016/j.progpolymsci.2014.03.001

[175] Demina T. S., Akopova T. A., Vladimirov L. V., Shchegolikhin A. N., Kechek'yan A. S., Perov N. S., Chernyshenko A. O., Zelenetskii A. N.: The study of the interaction between chitosan and 2,2-bis(hydroxymethyl) propionic acid during solid-phase synthesis. Polymer Science Series B, 53, 358-370 (2011). https://doi.org/10.1134/S1560090411060030

[176] Rogovina S. Z., Vikhoreva G. A., Akopova T. A., Gorbacheva I. N., Zelenetskii S. N.: Reactions of chitosan with solid carbonyl-containing compounds under shearing deformation conditions. Mendeleev Communications, 8, 107-109 (1998).

https://doi.org/10.1070/MC1998v008n03ABEH000923

[177] Bogomolova T. B., Kozlova N. V., Chvalun S. N.: Modification of chitosan via grafting of glycolic acid followed by polycondensation during heat treatment. Polymer Science Series B, 51, 352-359 (2009). https://doi.org/10.1134/S156009040909005X

[178] Kumari S., Singh R. P.: Glycolic acid-g-chitosan-Pt$\mathrm{Fe}_{3} \mathrm{O}_{4}$ nanoparticles nanohybrid scaffold for tissue engineering and drug delivery. International Journal of Biological Macromolecules, 51, 76-82 (2012). https://doi.org/10.1016/j.ijbiomac.2012.01.040

[179] Kumari S., Singh R. P.: Glycolic acid functionalized chitosan- $\mathrm{Au}-\mathrm{Fe}_{3} \mathrm{O}_{4}$ hybrid nanoparticle based nanohybrid scaffold for drug delivery. International Journal of Biological Macromolecules, 54, 244-249 (2013). https://doi.org/10.1016/j.ijbiomac.2012.12.001

[180] Kumari S., Singh R. P.: Glycolic acid-g-chitosan-gold nanoflower nanocomposite scaffolds for drug delivery and tissue engineering. International Journal of Biological Macromolecules, 50, 878-883 (2012). https://doi.org/10.1016/j.ijbiomac.2011.10.014

[181] Yao F., Chen W., Wang H., Liu H., Yao K., Sun P., Lin H.: A study on cytocompatible poly(chitosan- $g$-L-lactic acid). Polymer, 44, 6435-6441 (2003). https://doi.org/10.1016/S0032-3861(03)00676-1 
[182] Lai C., Chen Y., Zhang S.: Study on chitosan-lactate sponges with oriented pores as potential wound dressing. Materials Sciences and Applications, 4, 458-470 (2013).

https://doi.org/10.4236/msa.2013.48056

[183] Hu H., Wang X., Wang J., Liu F., Zhang M., Xu C.: Microwave-assisted covalent modification of graphene nanosheets with chitosan and its electrorheological characteristics. Applied Surface Science, 257, 2637 2642 (2011).

https://doi.org/10.1016/j.apsusc.2010.10.035

[184] Demina T. S., Akopova T. A., Vladimirov L. V., Zelenetskii A. N., Markvicheva E. A., Grandfils C.: Polylactide-based microspheres prepared using solid-state copolymerized chitosan and D,L-lactide. Materials Science and Engineering: C, 59, 333-338 (2016). https://doi.org/10.1016/j.msec.2015.09.094

[185] Liu L., Shi A., Guo S., Fang Y., Chen S., Li J.: Preparation of chitosan- $g$-polylactide graft copolymers via self-catalysis of phthaloylchitosan and their complexation with DNA. Reactive and Functional Polymers, 70, 301-305 (2010).

https://doi.org/10.1016/j.reactfunctpolym.2010.02.003

[186] Akopova T. A., Demina T. S., Shchegolikhin A. N., Kurkin T. S., Grandfils C., Perov N. S., Kechekyan A. S., Zelenetskii A. N.: A novel approach to design chitosan-polyester materials for biomedical applications. International Journal of Polymer Science, 2012, 827967/1-827967/10 (2012).

https://doi.org/10.1155/2012/827967

[187] Wang Q., Liu P., Liu P., Gong T., Li S., Duan Y., Zhang Z.: Preparation, blood coagulation and cell compatibility evaluation of chitosan-graft-polylactide copolymers. Biomedical Materials, 9, 015007/1015007/??? (2014).

https://doi.org/10.1088/1748-6041/9/1/015007

[188] Chen H., Huang J., Yu J., Liu S., Gu P.: Electrospun chitosan-graft-poly ( $\varepsilon$-caprolactone)/poly ( $\varepsilon$-caprolactone) cationic nanofibrous mats as potential scaffolds for skin tissue engineering. International Journal of Biological Macromolecules, 48, 13-19 (2011). https://doi.org/10.1016/j.ijbiomac.2010.09.019

[189] Lee K. Y., Ha W. S., Park W. H.: Blood compatibility and biodegradability of partially $N$-acylated chitosan derivatives. Biomaterials, 16, 1211-1216 (1995). https://doi.org/10.1016/0142-9612(95)98126-Y

[190] Jiang G-B., Quan D., Liao K., Wang H.: Preparation of polymeric micelles based on chitosan bearing a small amount of highly hydrophobic groups. Carbohydrate Polymers, 66, 514-520 (2006). https://doi.org/10.1016/j.carbpol.2006.04.008

[191] Neamnark A., Rujiravanit R., Supaphol P.: Electrospinning of hexanoyl chitosan. Carbohydrate Polymers, 66, 298-305 (2006).

https://doi.org/10.1016/j.carbpol.2006.03.015
[192] Hu R., Zheng H., Cao J., Davoudi Z., Wang Q.: Synthesis and in vitro characterization of carboxymethyl chitosan-CBA-doxorubicin conjugate nanoparticles as $\mathrm{pH}$-sensitive drug delivery systems. Journal of Biomedical Nanotechnology, 13, 1097-1105 (2017). https://doi.org/10.1166/jbn.2017.2407

[193] Mutasher S. H., Salih A. A., Al-Lami H. S.: Preparation of some chitosan derivatives and study their effect on human genetic material. Der Pharma Chemica, 8, 125-134 (2016).

[194] Sridhari T. R., Dutta P. K.: Synthesis and characterization of maleilated chitosan for dye house effluent. Indian Journal of Chemical Technology, 7, 198-201 (2000).

[195] Tikhonov V. E., Stepnova E. A., Babak V. G., Krayukhina M. A., Berezin B. B., Yamskov I. A.: Amphiphilic $N$-[2(3)-(dodec-2'-en-1'-yl)succinoyl]chitosan: Synthesis and properties. Reactive and Functional Polymers, 68, 436-445 (2008).

https://doi.org/10.1016/j.reactfunctpolym.2007.11.002

[196] Du Y-Z., Lu P., Zhou J-P., Yuan H., Hu F-Q.: Stearic acid grafted chitosan oligosaccharide micelle as a promising vector for gene delivery system: Factors affecting the complexation. International Journal of Pharmaceutics, 391, 260-266 (2010).

https://doi.org/10.1016/j.ijpharm.2010.02.017

[197] Du Y-Z., Wang L., Yuan H., Hu F-Q.: Linoleic acidgrafted chitosan oligosaccharide micelles for intracellular drug delivery and reverse drug resistance of tumor cells. International Journal of Biological Macromolecules, 48, 215-222 (2011).

https://doi.org/10.1016/j.ijbiomac.2010.11.005

[198] Du Y-Z., Wang L., Yuan H., Wei X-H., Hu F-Q.: Preparation and characteristics of linoleic acid-grafted chitosan oligosaccharide micelles as a carrier for doxorubicin. Colloids and Surfaces B: Biointerfaces, 69, 257263 (2009).

https://doi.org/10.1016/j.colsurfb.2008.11.030

[199] Ye Y-Q., Yang F-L., Hu F-Q., Du Y-Z., Yuan H., Yu H-Y.: Core-modified chitosan-based polymeric micelles for controlled release of doxorubicin. International Journal of Pharmaceutics, 352, 294-301 (2008). https://doi.org/10.1016/j.ijpharm.2007.10.035

[200] Li Q., Du Y-Z., Yuan H., Zhang X-G., Miao J., Cui FD., Hu F-Q.: Synthesis of lamivudine stearate and antiviral activity of stearic acid- $g$-chitosan oligosaccharide polymeric micelles delivery system. European Journal of Pharmaceutical Sciences, 41, 498-507 (2010). https://doi.org/10.1016/j.ejps.2010.08.004

[201] Hu F-Q., Wu X-L., Du Y-Z., You J., Yuan H.: Cellular uptake and cytotoxicity of shell crosslinked stearic acid-grafted chitosan oligosaccharide micelles encapsulating doxorubicin. European Journal of Pharmaceutics and Biopharmaceutics, 69, 117-125 (2008). https://doi.org/10.1016/j.ejpb.2007.09.018 
[202] di Martino A., Sedlarik V.: Amphiphilic chitosangrafted-functionalized polylactic acid based nanoparticles as a delivery system for doxorubicin and temozolomide $\mathrm{co}$-therapy. International Journal of Pharmaceutics, 474, 134-145 (2014).

https://doi.org/10.1016/j.ijpharm.2014.08.014

[203] Zhang X., Zhang H., Yin L., Hu R., Qiu T., Yin Y., Xiong X., Zheng H., Wang Q.: A pH-sensitive nanosystem based on carboxymethyl chitosan for tumortargeted delivery of daunorubicin. Journal of Biomedical Nanotechnology, 12, 1688-1698 (2016).

https://doi.org/10.1166/jbn.2016.2278

[204] Zuo P-P., Feng H-F., Xu Z-Z., Zhang L-F., Zhang YL., Xia W., Zhang W-Q.: Fabrication of biocompatible and mechanically reinforced graphene oxide-chitosan nanocomposite films. Chemistry Central Journal, 7, 39/1-39/11 (2013).

https://doi.org/10.1186/1752-153X-7-39
[205] Bonferoni M. C., Sandri G., Dellera E., Rossi S., Ferrari F., Zambito Y., Caramella C.: Palmitoyl glycol chitosan micelles for corneal delivery of cyclosporine. Journal of Biomedical Nanotechnology, 12, 231-240 (2016) https://doi.org/10.1166/jbn.2016.2140

[206] Guan X., Quan D., Shuai X., Liao K., Mai K.: Chitosan-graft-poly( $\varepsilon$-caprolactone)s: An optimized chemical approach leading to a controllable structure and enhanced properties. Journal of Polymer Science Part A: Polymer Chemistry, 45, 2556-2568 (2007). https://doi.org/10.1002/pola.22015 